\title{
WWP2 ubiquitylates RNA polymerase II for DNA-PK-dependent transcription arrest and repair at DNA breaks
}

\author{
Pierre Caron, ${ }^{1,10}$ Tibor Pankotai, ${ }^{2,3,4,5,7,10}$ Wouter W. Wiegant, ${ }^{1}$ Maxim A.X. Tollenaere, ${ }^{1,8}$ \\ Audrey Furst, ${ }^{2,3,4,5}$ Celine Bonhomme, ${ }^{2,3,4,5}$ Angela Helfricht, ${ }^{1,9}$ Anton de Groot, ${ }^{1}$ Albert Pastink, ${ }^{1}$ \\ Alfred C.O. Vertegaal, ${ }^{6}$ Martijn S. Luijsterburg, ${ }_{1}^{1}$ Evi Soutoglou, ${ }^{2,3,4,5}$ and Haico van Attikum ${ }^{1}$ \\ ${ }^{1}$ Department of Human Genetics, Leiden University Medical Center, 2333 ZC Leiden, The Netherlands; ${ }^{2}$ Institut de Génétique et \\ de Biologie Moléculaire et Cellulaire (IGBMC), 67404 Illkirch, France; ${ }^{3}$ U1258, Institut National de la Santé et de la Recherche \\ Médicale (INSERM), 67404 Illkirch, France; ${ }^{4}$ UMR7104, Centre National de Recherche Scientifique (CNRS), 67404 Illkirch, \\ France; ${ }^{5}$ Université de Strasbourg, 67081 Strasbourg, France; ${ }^{6}$ Department of Cell and Chemical Biology, Leiden University \\ Medical Center, 2333 ZC Leiden, The Netherlands
}

DNA double-strand breaks (DSBs) at RNA polymerase II (RNAPII) transcribed genes lead to inhibition of transcription. The DNA-dependent protein kinase (DNA-PK) complex plays a pivotal role in transcription inhibition at DSBs by stimulating proteasome-dependent eviction of RNAPII at these lesions. How DNA-PK triggers RNAPII eviction to inhibit transcription at DSBs remains unclear. Here we show that the HECT E3 ubiquitin ligase WWP2 associates with components of the DNA-PK and RNAPII complexes and is recruited to DSBs at RNAPII transcribed genes. In response to DSBs, WWP2 targets the RNAPII subunit RPB1 for K48-linked ubiquitylation, thereby driving DNA-PK- and proteasome-dependent eviction of RNAPII. The lack of WWP2 or expression of nonubiquitylatable RPB1 abrogates the binding of nonhomologous end joining (NHEJ) factors, including DNA-PK and XRCC4/DNA ligase IV, and impairs DSB repair. These findings suggest that WWP2 operates in a DNA-PK-dependent shutoff circuitry for RNAPII clearance that promotes DSB repair by protecting the NHEJ machinery from collision with the transcription machinery.

[Keywords: DNA double-strand break repair; transcription silencing; DNA-PK; WWP2 HECT E3 ubiquitin ligase; RNAPII ubiquitylation]

Supplemental material is available for this article.

Received October 22, 2018; revised version accepted March 25, 2019.

DNA double-strands breaks (DSBs) are a threat to the integrity of our genome. If left unrepaired or repaired inaccurately, they can lead to chromosomal rearrangements or loss of genetic information. While DSBs can be repaired by either homologous recombination (HR) or alternative end joining (alt-EJ), canonical nonhomologous end joining (cNHEJ) is the predominant repair pathway that seals the two broken ends together with or without minimal homology (Deriano and Roth 2013; Chang et al. 2017; Pannunzio et al. 2018). Since DSBs can occur in inactive and actively transcribed regions, an intimate interplay between these repair mechanisms and transcription is required to

Present addresses: ${ }^{7}$ Department of Biochemistry and Molecular Biology, University of Szeged, Szeged, 6726, Hungary; ${ }^{8}$ LEO Pharma A/S, 2750 Ballerup, Denmark; 'Department of Molecular Genetics, Oncode Institute, Erasmus MC, University Medical Center Rotterdam, 3015 GD Rotterdam, The Netherlands.

${ }^{10}$ These authors contributed equally to this work Corresponding authors: h.van.attikum@lumc.nl, evisou@igbmc.fr Article published online ahead of print. Article and publication date are online at http://www.genesdev.org/cgi/doi/10.1101/gad.321943.118. Freely available online through the Genes \& Development Open Access option. preserve genome stability and control transcriptional programs.

While DNA damage to the transcribed strand directly blocks RNA polymerase II (RNAPII) progression, DSBs lead to arrest of RNAPII transcription in a manner dependent on the PI3K-like kinases ataxia telangiectasia mutated (ATM) and DNA-dependent protein kinase catalytic subunit (DNA-PKcs) as well as the poly(ADP-ribose) polymerase 1 (PARP1) enzyme (Marnef et al. 2017; Ray Chaudhuri and Nussenzweig 2017). In response to clustered DSBs induced by the FokI or I-SceI endonucleases, ATM will rapidly trigger transcription silencing of DSBflanking genes by regulating the establishment and spreading of a histone-repressive mark, H2AK119ub, and of Lys11-linked ubiquitin conjugates on $\mathrm{H} 2 \mathrm{~A} / \mathrm{H} 2 \mathrm{AX}$. $\mathrm{H} 2 \mathrm{AK} 119 \mathrm{ub}$ is catalyzed by the E3 ubiquitin ligases RNF8/RNF168 and Ring1B, which is a component of polycomb-repressive complex 1 (PRC1) and PRC2. In

(C) 2019 Caron et al. This article, published in Genes \& Development, is available under a Creative Commons License (Attribution 4.0 International), as described at http://creativecommons.org/licenses/by/4.0/. 
addition, RNF8 is also involved in catalyzing K11-linked ubiquitin moieties on $\mathrm{H} 2 \mathrm{~A} / \mathrm{H} 2 \mathrm{AX}$ (Paul and Wang 2017). While RNF8/RNF168 recruitment relies on ATMdependent phosphorylation of H2AX and MDC1 (Dantuma and van Attikum 2016), Ring1B is recruited through ATM-dependent phosphorylation of the superelongating complex (SEC) and the PBAF chromatin remodeling complex (Shanbhag et al. 2010; Kakarougkas et al. 2014; Ui et al. 2015). Importantly, these ATM-driven mechanisms for transcription silencing are critical for proper DSB repair through NHEJ.

Besides ATM, PARP1 also promotes transcription silencing near clustered DSBs. This involves the PARP1dependent recruitment and activities of histone demethylase KDM5a and the ZMYND8-NuRD complex at DSBs (Chou et al. 2010; Gong et al. 2015, 2017; Spruijt et al. 2016). Moreover, PARP1 mediates recruitment of the NELF complex (Awwad et al. 2017), a negative regulator of transcription, which has been described to regulate RNAPII pausing at promoters shortly after transcription initiation (Li et al. 2013). Finally, PARP1 triggers the recruitment of chromodomain protein Y-like (CDYL1), which negatively regulates transcription through histone H3K27 methylation (Abu-Zhayia et al. 2018). While NELF promotes DSB repair via both NHEJ and HR, KDM5a, ZMYND8-NuRD, and CDYL1 promote DSB repair through HR only (Gong et al. 2015, 2017; Abu-Zhayia et al. 2018). Together, these studies revealed that ATM and PARP1 silence transcription of genes that flank DSBs by triggering extensive chromatin remodeling around the damage, thereby promoting efficient repair by NHEJ and HR. It is unclear whether these processes trigger transcription silencing by directly regulating RNAPII itself.

In the case of unique nonclustered DSBs introduced by, for instance, the I-PpoI endonuclease into transcribed genes, repression of transcription is regulated at the level of RNAPII itself and is mediated by the DNA-PK complex (Pankotai et al. 2012). Activated DNA-PK is responsible for the arrest and release of elongating RNAPII, the latter of which involves proteasome activity (Pankotai et al. 2012). However, it is unclear how DNA-PKcs triggers proteasome-dependent transcriptional silencing of broken genes. In this study, we identify the HECT E3 ubiquitin ligase WWP2 as a critical mediator of transcription silencing at DSBs. WWP2 acts in a DNA-PKcs-dependent manner to target RNAPII for ubiquitylation and subsequent degradation by the proteasome, thereby promoting transcription repression and DSB repair by cNHEJ.

\section{Results}

WWP2 protects cells against DSBs by promoting NHEJ

An RNAi-based genome-wide screen in Caenorhabditis elegans identified Ce-wwp-1 as a novel gene that protects cells against ionizing radiation (IR) (van Haaften et al. 2006). We assessed whether the human homolog of $\mathrm{Ce}$ $W w p-1$, the WWP2 gene, plays a similar role. To this end, two independent siRNAs were used to deplete WWP2 in VH10-SV40 immortalized human fibroblasts (Supplemen- tal Fig. S1A), and clonogenic survival of these cells was determined following exposure to IR. WWP2-depleted cells were markedly more sensitive to IR when compared with control cells (siLuc), although not to the same extent as cells depleted of the core NHEJ factor XRCC4 (Fig. 1A). Thus, WWP2 protects human cells against the clastogenic effects of IR (van Haaften et al. 2006), suggesting a role for WWP2 in the repair of IR-induced DNA damage.

IR induces a variety of DNA lesions, including highly deleterious DNA DSBs, which are predominantly repaired by NHEJ. To determine whether WWP2 affects this repair process, we used the well-established EJ5-GFP assay for NHEJ repair of I-SceI nuclease-induced DSBs (Supplemental Fig. 1B; Bennardo et al. 2008). Depletion of RNF8, an E3 ubiquitin ligase known to be involved in NHEJ (Butler et al. 2012), greatly reduced NHEJ (Fig. 1B). Importantly, we also found that depletion of WWP2 markedly reduced NHEJ (Fig. 1B; Supplemental Fig. S1C). The EJ5-GFP reporter provides a readout for total NHEJ activity (cNHEJ and alternative NHEJ) (Bennardo et al. 2008). To examine whether WWP2 plays a role specifically in cNHEJ, we monitored random plasmid integration into the human genome, which we and others have shown to be largely dependent on cNHEJ (Supplemental Fig. S1D; Galanty et al. 2009; Agarwal and Jackson 2016; Luijsterburg et al. 2016). Indeed, depletion of the core cNHEJ factors Ku80 and DNA-PKcs dramatically reduced cNHEJ (Fig. 1C), whereas depletion of BRCA2, required for HR-mediated DSB repair, did not impair this process (and may even lead to a slight increase) (Luijsterburg et al. 2016). Importantly, WWP2 depletion decreased the NHEJ efficiency by $\sim 60 \%$. Thus, our results suggest that WWP2 is a novel factor that promotes DSB repair by NHEJ.

\section{WWP2 interacts with NHEJ proteins and members of the RNAPII complex}

To study how WWP2 affects DSB repair, we set out to identify proteins that interact with WWP2. To this end, we generated U2OS cells stably expressing GFP-tagged WWP2. Pull-downs of GFP-WWP2 from these cells followed by mass spectrometry (MS) after stable isotope labeling by amino acids in culture (SILAC) revealed 621 proteins that were at least twofold enriched compared with control cells (Supplemental Table S1). Our analysis revealed Ku80, PARP1, and the histone demethylase PHF8, all of which regulate DSB repair by NHEJ (Fig. 1D; Fell and SchildPoulter 2015; Luijsterburg et al. 2016; Wang et al. 2016). In addition, we also identified 11 of the 12 subunits of the RNAPII complex (Fig. 1D; Wild and Cramer 2012). Among these was RPB1 (POLR2A), whose phosphorylation and ubiquitylation are critical for transcription regulation under physiological as well as DNA damage conditions (Ratner et al. 1998; Somesh et al. 2005, 2007; Sordet et al. 2008; Yasukawa et al. 2008; Verma et al. 2011; Hsin and Manley 2012; Jeronimo et al. 2016).

Reciprocal GFP pull-downs coupled to Western blot analysis confirmed that GFP-tagged WWP2 interacts with endogenous Ku80 in U2OS cells and that GFP-tagged $\mathrm{Ku} 80$ interacts with endogenous WWP2 in HeLa cells (Fig. 

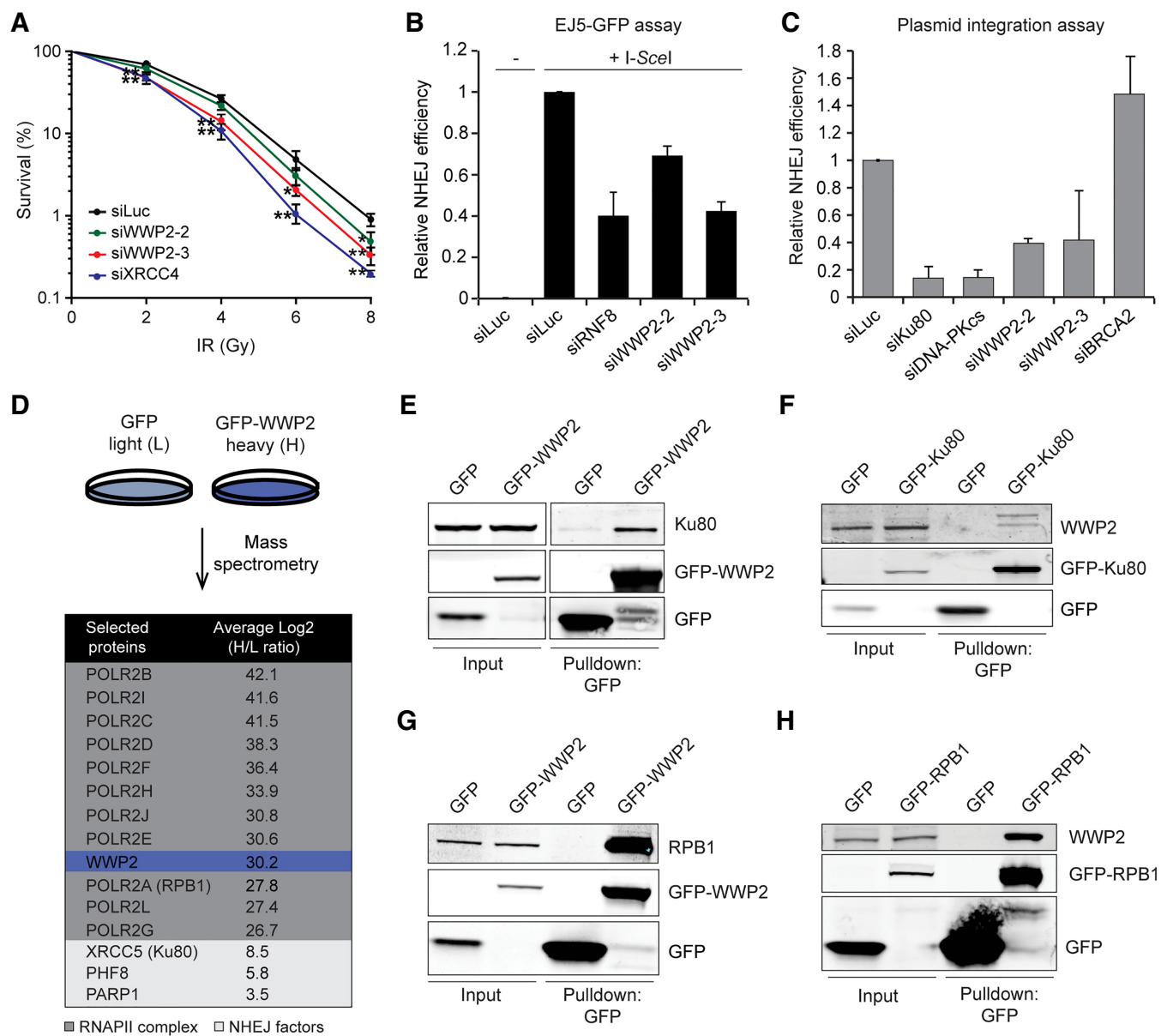

Figure 1. WWP2 protects cells against DSBs by promoting NHEJ. (A) Clonogenic survival of VH10-SV40 cells transfected with the indicated siRNAs and exposed to the indicated doses of IR. The mean \pm SD from three independent experiments is shown. Statistical significance was calculated using the Student's $t$-test. $\left({ }^{*}\right) P<0.05 ;(* *) P<0.01$. (B) Quantification of GFP-positive EJ5-GFP HEK293 cells transfected with the indicated siRNAs. DSBs were induced by transfection of an I-SceI expression vector. The transfection efficiency was corrected by cotransfection with an mCherry expression vector. The mean $\pm \mathrm{SD}$ from two independent experiments is shown. $(C)$ Quantification of plasmid integration efficiencies in U2OS cells transfected with the indicated siRNAs. The mean \pm SD from two independent experiments is shown. (D) SILAC (stable isotope labeling by amino acids in culture)-based mass spectrometry analysis of stable U2OS cells expressing GFP (L) or GFP-WWP2 (H). RNAPII complex members are marked in dark gray, whereas NHEJ factors are indicated in light gray. (E) Pull-downs of the indicated GFP fusion proteins in U2OS cells. Blots were probed for Ku80 and GFP. $(F)$ Pull-downs of the indicated GFP fusion proteins in HeLa cells. Blots were probed for WWP2 and GFP. $(G)$ As in $E$, except that blots were probed for RPB1 and GFP. $(H)$ As in $E$, except that blots were probed for WWP2 and GFP.

$1 \mathrm{E}, \mathrm{F})$. Moreover, using the same approach, we also confirmed the interaction between GFP-tagged WWP2 and endogenous RPB1 (Fig. 1G). To confirm the interaction between GFP-WWP2 and RPB1 in a reciprocal manner, we established U2OS cells stably expressing GFP-tagged RPB1 that is resistant to the RNAPII inhibitor $\alpha$-amanitin (Supplemental Fig. S1E,F; Darzacq et al. 2007; Dias et al. 2015). Expression of endogenous RPB1 was lost in these cells upon treatment with a-amanitin (Supplemental Fig. $\mathrm{S} 1 \mathrm{E}, \mathrm{F})$. Moreover, we detected the elongating form of GFP-RPB1 (p-GFP-RPB1 S2), indicating that GFP-tagged RPB1 functionally replaced endogenous RPB1 in these cells. Importantly, using these cells, we also observed that GFP-RPB1 interacts with endogenous WWP2 (Fig. $1 \mathrm{H})$. Together, our results show that WWP2 not only interacts with the core NHEJ factor Ku80 but also associates with the RNAPII complex, the latter of which agrees with a previous report (Li et al. 2007). Moreover, these findings suggest a potential role for WWP2 in regulating RNAPII during NHEJ.

\section{WWP2 is recruited to DSBs in transcribed genes to promote DNA repair}

WWP2 has been shown to play a role in transcription regulation (Li et al. 2007; Marcucci et al. 2011; Scheffner and Kumar 2014). This raised the possibility that WWP2 affects DSB repair indirectly by regulating the RNAPIIdependent expression of NHEJ factors. However, we found that the expression of several factors involved in NHEJ was comparable with that in control cells (Supplemental Fig. S2A). Alternatively, WWP2 may play a direct role in 
NHEJ by acting at sites of DNA damage. To examine this, we monitored whether WWP2 is recruited to multiphoton laser-inflicted DNA damage. U2OS cells were cotransfected with expression vectors for mCherrytagged WWP2 and GFP-tagged Ku70, a core NHEJ factor that served as a positive control for recruitment. Livecell imaging after laser microirradiation indeed revealed that, similar to GFP-Ku70, mCherry-WWP2 rapidly accumulates at sites of DNA damage (Fig. 2A,B; Kochan et al. 2017). However, whereas GFP-Ku70 reached maximum levels of accumulation at $100 \mathrm{sec}$ and remained associated with the DNA damage during the course of the experiment, mCherry-WWP2 transiently associated, reaching maximum levels at $50 \mathrm{sec}$ and returning to near-basal levels at $150 \mathrm{sec}$ (Fig. 2B). Similar recruitment dynamics were observed in stable cells expressing GFPWWP2 (Fig. 2F,G).

Since WWP2 interacts with the RNAPII complex, we next addressed whether it is recruited to bona fide DSBs that occur within transcribed genes. To explore this

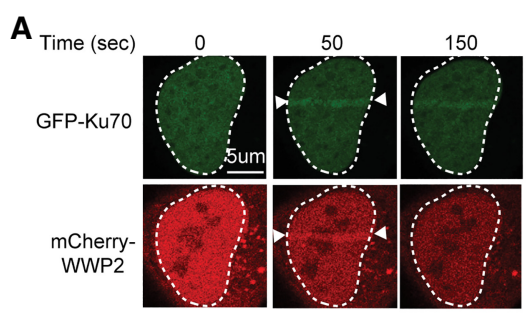

B

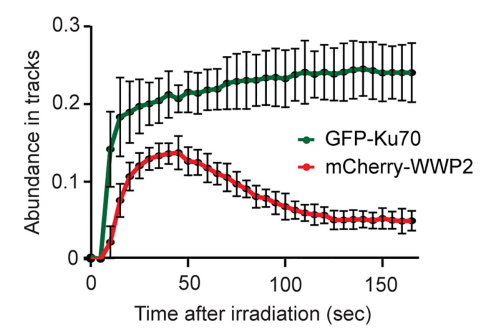

C

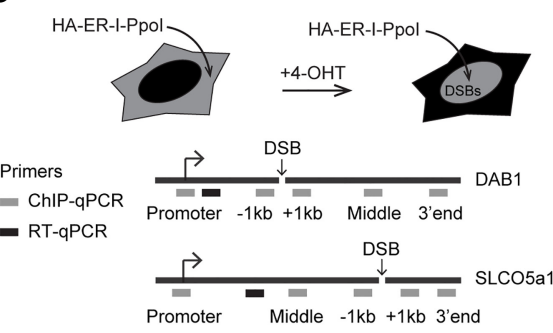

D
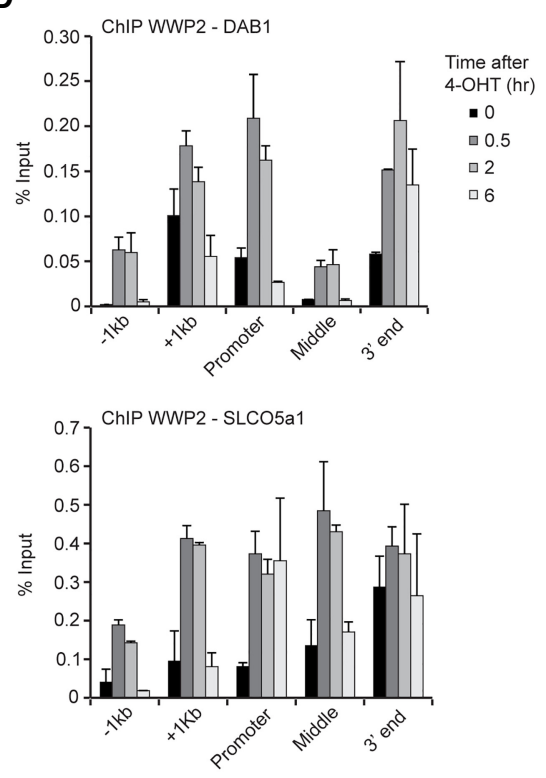

E

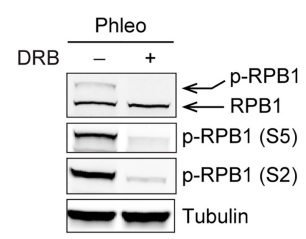

$\mathbf{F}$

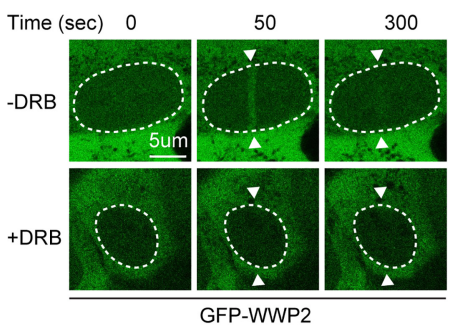

G

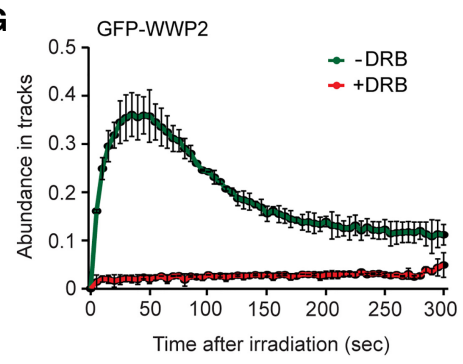

H
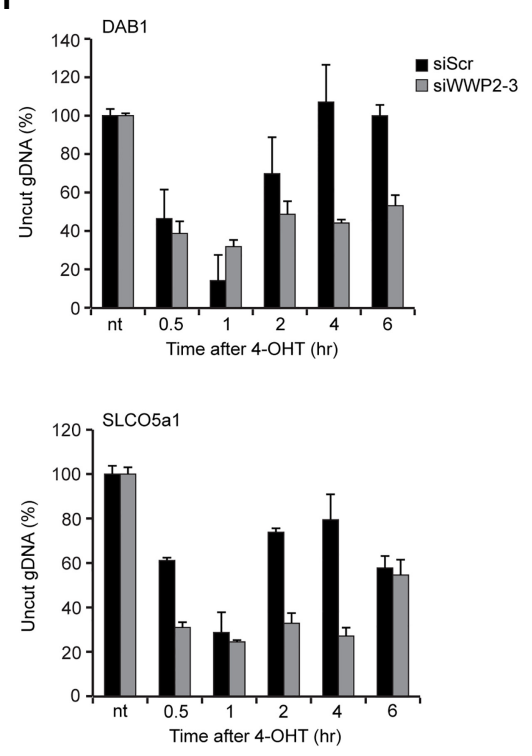

Figure 2. WWP2 is recruited to DSBs in transcribed genes to promote DNA repair. (A) Recruitment of mCherry-WWP2 to multiphoton tracks in U2OS cells. GFP-Ku70 was used as a DNA damage marker. (B) Quantification of $A$. (C) Schematic of the HA-ER-I-PpoI system in U2OS cells used to generate site-specific DSBs at the indicated genes following 4-hydroxytamoxifen (4-OHT) treatment. Gray boxes indicate positions where protein binding is monitored by ChIP-qPCR (chromatin immunoprecipitation [ChIP] combined with quantitative PCR [qPCR]). Black boxes indicate positions of the primers used to quantify mRNA levels of the indicated genes by RT-qPCR. (D) ChIPqPCR against WWP2 in U2OS HA-ER-I-PpoI cells at the indicated time points after 4OHT treatment and at the indicated positions at DAB1 and SLCO5a1. The mean \pm SD from qPCR replicates of a representative experiment is shown. A repeat of the experiment is shown in Supplemental Figure S2C. (E) Western blot analysis of RPB1 and Ser2and Ser5-phosphorylated RPB1 (S2 and S5) levels in phleomycin (Phleo)-treated U2OS cells that were left untreated or were treated with 5,6-dichloro-1- $\beta$-D-ribofuranosylbenzimidazole (DRB). Tubulin was used as a loading control. $(F)$ Recruitment of GFP-WWP2 to multiphoton tracks in untreated and DRB-treated U2OS cells. (G) Quantification of $F .(H)$ Cutting efficiencies at DAB1 and SLCO5a1 at the indicated time points after 4-OHT treatment in U2OS HA-ER-I-PpoI cells transfected with the indicated siRNAs. The mean \pm SD from qPCR replicates of a representative experiment is shown. A repeat of the experiment is shown in Supplemental Figure S8A. 
possibility, we expressed the site-specific I-PpoI meganuclease tagged with HA and estrogen receptor (ER) from a doxycycline (Dox)-inducible promoter in U2OS cells (U2OS-pEP15) to introduce a unique DSB in several transcribed genes (Fig. 2C; Supplemental Fig. S2B; Pankotai et al. 2012). We then performed chromatin immunoprecipitation (ChIP) experiments against endogenous WWP2 and monitored its levels before and at different time points after DSB induction in two of the actively transcribed genes: DAB1 and SLCO5a1. Two other actively transcribed genes, INTS4 and p21, without DSB served as controls. We found that WWP2 is recruited to DSBs induced at $D A B 1$ and SLCO5a1, reaching maximum levels between $30 \mathrm{~min}$ and $2 \mathrm{~h}$ and returning to near-basal levels at $6 \mathrm{~h}$ at all positions except for the $3^{\prime}$ end of these genes (Fig. 2D; Supplemental Fig. S2C). In contrast, WWP2 did not accumulate at the nondamaged INTS 4 and $p 21$ genes (Supplemental Fig. S2D). Next, we asked whether the recruitment of WWP2 to DSBs in active genes is dependent on RNAPII-driven transcription. To this end, stable GFPWWP2 cells were treated with the DSB-inducing agent phleomycin and 5,6-dichloro-1- $\beta$-D-ribofuranosylbenzimidazole (DRB), which inhibits RNAPII transcription as revealed by a reduction in the levels of Ser5-phosphorylated (initiating form) and Ser2-phosphorylated (elongating form) RPB1 (Fig. 2E; Jeronimo et al. 2016). Laser microirradiation of these cells showed that DRB treatment completely abrogated the transient recruitment of GFPWWP2 (Fig. 2F,G), indicating that active RNAPII-mediated transcription is required for the accumulation of WWP2 at sites of DNA damage.

We then determined whether loss of WWP2 may impact the efficiency of DSB repair in DAB1 and SLCO5a1 as well as in another actively transcribed gene, $R Y R 2$, which can be cleaved by I-PpoI. To this end, we used our previously established quantitative PCR (qPCR)-based assay, which determines DSB repair by comparing the amplification of DNA products across the I-PpoI cleavage sites before and after DSB induction (Pankotai et al. 2012). DSB induction reached a plateau between $30 \mathrm{~min}$ and $1 \mathrm{~h}$, while repair of the breaks was detected after 4-6 h in control cells (siScr) (Fig. 2H; Supplemental Figs. S2E, F, S8A). Importantly, depletion of WWP2 did not affect the efficiency of DSB formation, as monitored by our qPCR-based assay as well as by ChIP for $\gamma \mathrm{H} 2 \mathrm{AX}$ (Supplemental Figs. S2G,H, S9). However, we found that most DSBs remained unrepaired at 4-6 h after DSB induction, suggesting that the loss of WWP2 strongly impacted the repair of these lesions (Fig. $2 \mathrm{H}$; Supplemental Figs. S2E,F, S8A). Together, these results demonstrate that WWP2 is recruited to DSBs in actively transcribed genes to promote efficient repair of these DNA lesions.

\section{WWP2 represses transcription following DSB induction} in active genes

We reported previously that DSBs within transcribed genes induce transcription arrest through RNAPII eviction in cis (Pankotai et al. 2012). In order to assess a potential role of WWP2 in this process, we first measured the
mRNA levels of DAB1, SLCO5a1, and RYR2 before and after DSB induction by I-PpoI using RT-qPCR. We observed a rapid and strong decrease of the mRNA levels between $30 \mathrm{~min}$ and $1 \mathrm{~h}$ after DSB induction, while a return to basal levels was detected between 4 and $6 \mathrm{~h}$ when repair of the damage was achieved (Fig. 3A,B, Supplemental Figs. S3A, S8B). However, following WWP2 depletion, mRNA levels remained stable for at least $1-2 \mathrm{~h}$ after DSB induction and decreased only after $4 \mathrm{~h}$, returning to basal levels at $6 \mathrm{~h}$. These results suggest that WWP2 mediates an efficient arrest of transcription at broken genes.

Inhibition of nascent transcription at sites of DNA damage inflicted by UV-A laser microirradiation was observed by monitoring the levels of nascent transcripts using 5ethynyl uridine (5-EU) incorporation (Supplemental Fig. S3B; Gong et al. 2015). Using this approach, we also found that in control cells, the transcription arrest at DNA damage sites is manifested by a decrease in EU incorporation (Supplemental Fig. S3C,D). However, the levels of nascent transcripts did not decrease dramatically when either CHD4 (a positive control) or WWP2 was depleted (Supplemental Fig. S3C,D), confirming that WWP2 promotes transcription silencing at sites of DNA damage.

Next, we examined whether WWP2 regulates transcription arrest at broken genes by affecting RNAPII occupancy. To this end, we performed ChIP against RPB1 and measured its levels at different positions around the I-PpoI-induced DSBs in DAB1 and SLCO5a1. We found that the level of RPB1 dramatically decreases along the broken genes at $30 \mathrm{~min}$ after DSB induction (Fig. 3C,D; Supplemental Fig. S8C,D). Importantly, following WWP2 depletion, we did not detect a rapid and strong RPB1 decrease at $30 \mathrm{~min}$ but rather at $6 \mathrm{~h}$ after DSB induction. In contrast, RPB1 occupancy at two actively transcribed $D A B 1$-flanking genes-OMA1 and PRKAA2, which lack I-PpoI cleavage sites (Pankotai et al. 2012)-was unchanged following DSB induction at $D A B 1$ irrespective of WWP2 depletion (Fig. 3E; Supplemental Fig. S8E). Altogether, these results reveal that efficient transcription arrest at broken genes is mediated by WWP2-dependent RNAPII eviction in cis.

\section{DSBs induce RPB1 ubiquitylation through WWP2}

Given that WWP2 is a HECT E3 ubiquitin ligase, we next asked whether WWP2 could regulate RNAPII at DSBs by targeting one or more components of the RNAPII complex for ubiquitylation. In mice, it was shown that WWP2 can ubiquitylate the RPB1 subunit of RNAPII, thereby targeting it for proteasomal degradation (Li et al. 2007). This raised the possibility that human RPB1 also becomes targeted by WWP2, possibly in response to DSBs, as a mean to evict RNAPII from these lesions. To investigate this, we first examined whether RPB1 becomes ubiquitylated in response to DSB induction. U2OS cells stably expressing GFP-RPB1 were exposed to phleomycin, etoposide, doxorubicin, and neocarzinostatin, which are agents that induce DSBs (Goodarzi et al. 2008; Mehta and Haber 2014; Yang et al. 2015). Cells were also exposed to UV irradiation, which generates photolesions that have been 

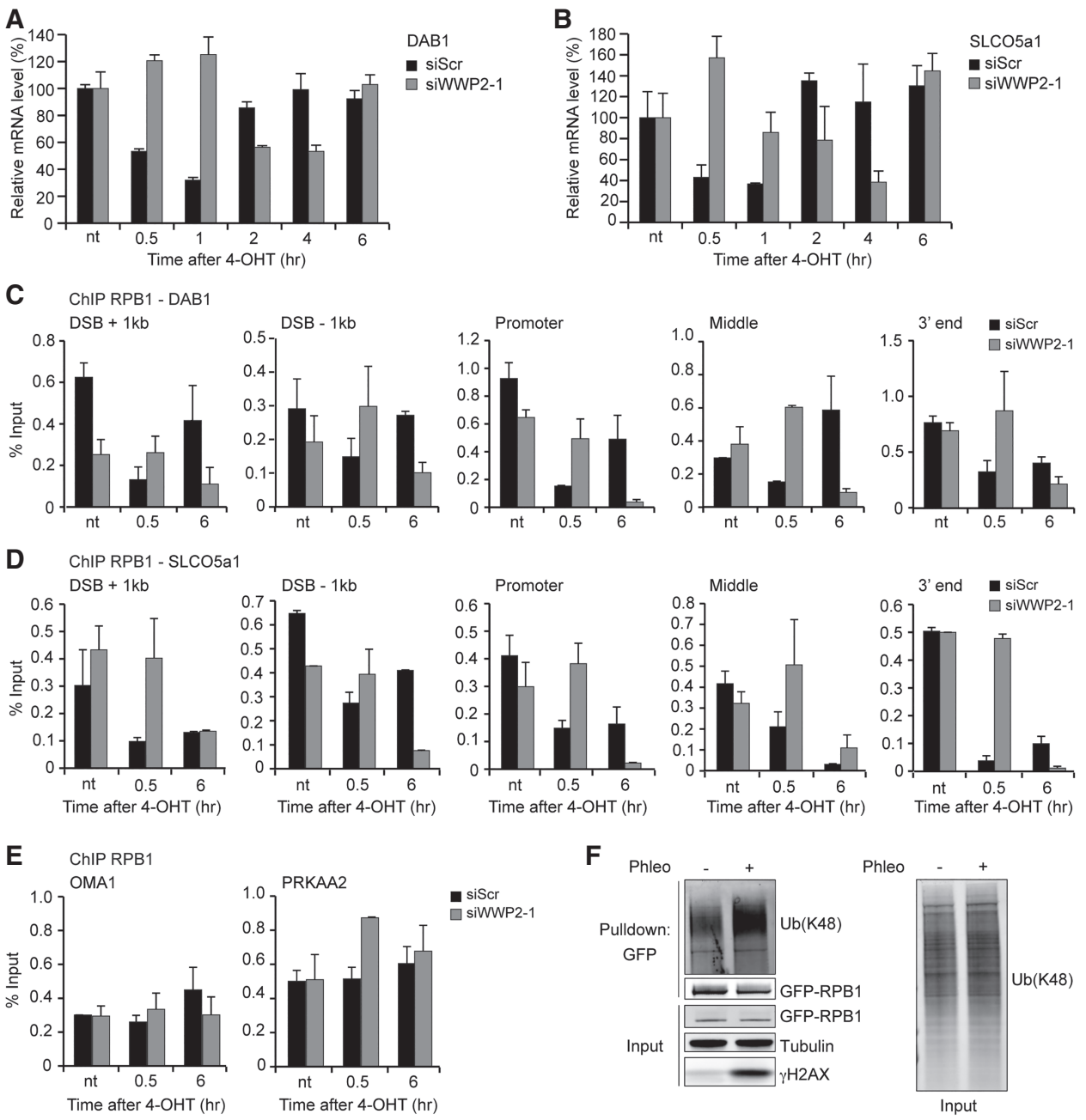

G
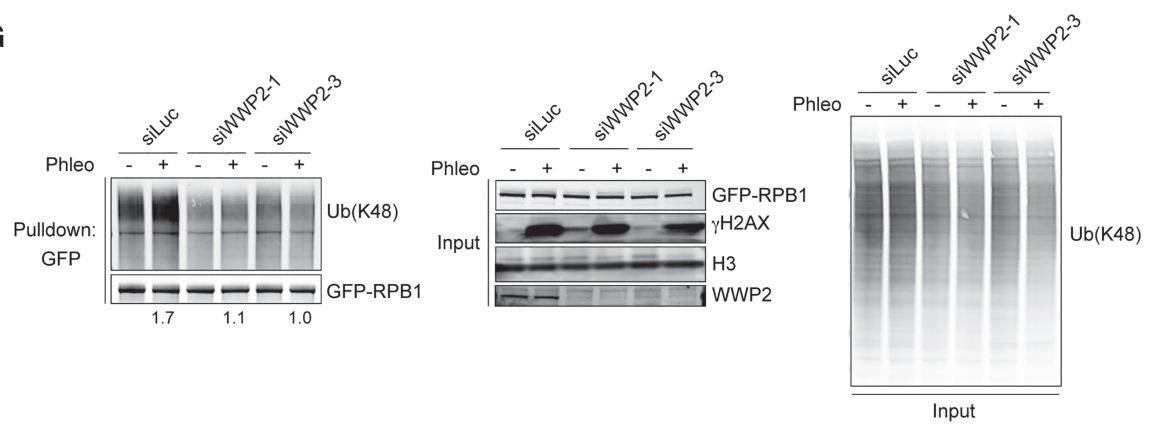

Figure 3. WWP2 promotes DSB-induced transcription silencing and RPBI ubiquitylation after DNA damage. (A) RT-qPCR analysis of $D A B 1$ expression levels in U2OS HA-ER-I-PpoI cells at the indicated time points after 4-OHT treatment and transfected with the indicated siRNAs. DAB1 mRNA levels were normalized to those of cyclophilin B. The mean \pm SD from qPCR replicates of a representative experiment is shown. A repeat of the experiment is shown in Supplemental Figure S8B. $(B)$ As in A, except for SLCO5a1. A repeat of the experiment is shown in Supplemental Figure S8B. (C) ChIP-qPCR against RPB1 in U2OS HA-ER-I-PpoI cells transfected with the indicated siRNAs. RPB1 levels were monitored at the indicated time points after 4-OHT treatment and at the indicated positions at DAB1. The mean \pm SD from qPCR replicates of a representative experiment is shown. A repeat of the experiment is shown in Supplemental Figure S8C. (D) As in $C$, except for SLCO5a1. A repeat of the experiment is shown in Supplemental Figure S8D. (E) ChIP-qPCR against RPB1 in U2OS HA-ER-I-PpoI cells transfected with the indicated siRNAs. RPB1 levels were monitored at the indicated time points after 4-OHT treatment at the OMA1 and PRKAA2 genes. The mean \pm SD from qPCR replicates of a representative experiment is shown. A repeat of the experiment is shown in Supplemental Figure S8E. $(F)$ Pull-downs of GFP-RPB1 under denaturing conditions in untreated and phleomycin (Phleo)-treated U2OS cells. Cells were also treated with proteasome inhibitor (MG-132) 25 min before the phleomycin treatment. Blots were probed for $\mathrm{Ub}(\mathrm{K} 48)$, GFP, and $\gamma \mathrm{H} 2 \mathrm{AX}$. Tubulin was used as a loading control. (G) As in $F$, except that cells were treated with the indicated siRNAs, and blots were also probed for H3. Relative Ub(K48) levels after GFP-RPB1 pull-down from phleomycin-treated versus untreated cells are indicated below the blots. 
shown previously to trigger ubiquitylation of RPB1 (Bregman et al. 1996; Ratner et al. 1998). Subsequently, GFP pull-downs were performed under denaturing conditions, after which the ubiquitylation status of RPB1 was monitored. RPB1's ability to interact with other proteins, such as the RNAPII subunit RPB2, was impaired under these conditions (Supplemental Fig. S3E). Moreover, we detected a clear increase in the ubiquitylation of RPB1 following UV irradiation (Supplemental Fig. S3F), agreeing with earlier work and validating our experimental setup (Bregman et al. 1996; Ratner et al. 1998). Interestingly, we found that the exposure of cells to phleomycin, etoposide, doxorubicin, or neocarzinostatin triggers robust K48linked ubiquitylation of RPB1, suggesting that this posttranslational modification of RPB1 can be induced by DSBs (Fig. 3F; Supplemental Fig. S3G,H). However, following WWP2 depletion, we found the phleomycin-induced RPB1 K48-linked ubiquitylation to be dramatically impaired (Fig. 3G). Reciprocal pull-downs using tandem ubiquitin-binding entities (TUBEs) confirmed that RPB1 is ubiquitylated following DSB induction by phleomycin and that this process is impaired when WWP2 is depleted (Supplemental Fig. S3I). These findings demonstrate that DSBs can trigger RPB1 ubiquitylation in a manner dependent on the WWP2 HECT E3 ubiquitin ligase.

\section{DNA-PK shuts off transcription through WWP2- dependent RPB1 ubiquitylation}

We reported previously that DSB-induced transcription arrest is regulated by the DNA-PK complex (Pankotai et al. 2012), whose kinase activity can trigger the eviction of RNAPII from broken genes. However, it remained unclear whether DNA-PK affects this process by regulating RPB1 ubiquitylation. To examine this, we performed GFP pulldowns using U2OS cells stably expressing GFP-RPB1. The cells were treated with phleomycin in the absence and presence of an inhibitor against DNA-PK. Western blot analysis detected a strong K48-linked ubiquitylation of RPB1 after phleomycin, which was dramatically reduced following DNA-PK inhibition (Fig. 4A). This result was confirmed in reciprocal pull-downs using the TUBE approach after DNA-PK depletion (Supplemental Fig. S4A,B). In line with this finding, we also observed that the depletion of DNA-PKcs or Ku80, an essential component of the DNA-PK complex, abolished RPB1 ubiquitylation induced by phleomycin (Fig. 4B; Supplemental Fig. $\mathrm{S} 4 \mathrm{C})$. In contrast, depletion of the cNHEJ ligase LigIV did not affect phleomycin-induced RPB1 ubiquitylation, suggesting that DNA-PK is the key NHEJ factor that regulates this process (Supplemental Fig. S4C).

Given that the phleomycin-induced ubiquitylation of RPB1 also relies on WWP2, we examined how DNA-PK and WWP2 cooperate to regulate this process. To this end, we inhibited DNA-PK in cells depleted of WWP2 and examined RBP1's ubiquitylation status following phleomycin treatment. As expected, DNA-PK inhibition or depletion of WWP2 alone reduced DNA damageinduced RPB1 ubiquitylation. Strikingly, the combined loss of DNA-PK activity and WWP2 protein did not aggra- vate this effect (Supplemental Fig. S4D). These results suggest that DNA-PK inhibits transcription of broken genes by regulating the WWP2-dependent ubiquitylation of the RNAPII subunit RPB1. To assess whether DNA-PK and WWP2 specifically affect RPB1 ubiquitylation or impact K48 ubiquitylation more globally, we monitored their effect on K48 ubiquitylation at laser-induced DNA damage tracks. Remarkably, we found that DNA-PK inhibition or WWP2 depletion did not impact the levels of K48 ubiquitylation in these tracks (Supplemental Fig. S4E-G). We infer that WWP2 and DNA-PK most prominently affect RPB1 ubiquitylation at DSBs, although we cannot exclude the possibility that WWP2 (possibly in a DNA-PK-dependent manner) targets DSB-associated proteins other than RPB1.

DSBs lead to the eviction of RPB1 not only proximal to DSB sites but also along broken genes. We therefore wondered whether the different steps of transcription, initiation, and elongation would be differentially affected by DSBs (Epshtein and Nudler 2003; Pankotai et al. 2012). To answer this question, we performed ChIP experiments against initiating (phospho-S5-RPB1), elongating (phospho-S2-RPB1), or initiating and elongating (phospho-S7RPB1) RPB1 (Jeronimo et al. 2016). Similar to RPB1, all phospho-RPB1 forms (S2, S5, and S7) were dramatically reduced after DSB induction along the entire gene, reaching maximum loss at $2 \mathrm{~h}$ (Fig. 4C,D; Supplemental Figs. S5A, S10A,B, S11A,B). However, DNA-PK inhibition did not lead to any decrease in RPB1 and phospho-RPB1 (S2, S5, and S7) levels (Fig. 4C,D; Supplemental Figs. S5A, S10A, $\mathrm{B}, \mathrm{S} 11 \mathrm{~A}, \mathrm{~B})$. In contrast, the occupancy of RPB1 and phospho-RPB1 (S2, S5, and S7) on the OMA1 and PRKAA2 genes, which are in close proximity to the I-PpoI-induced DSB at DAB1 and within the $\gamma \mathrm{H} 2 \mathrm{AX}$-enriched domains induced by this break, was unchanged irrespective of DNA-PK inhibition (Supplemental Figs. S5B,C, S12A,B). Together, these results show that DNA-PK is required to repress RNAPII transcription at DSBs by triggering WWP2-dependent K48-linked ubiquitylation and eviction of RPB1.

\section{Proteasomes are recruited to broken genes to target RNAPII complexes}

We next asked how the K48-linked ubiquitylation of RPB1 could lead to the eviction of RNAPII from broken genes. Polyubiquitylation and degradation of RNAPII by the proteasome system has been shown to resolve stalled RNAPII complexes on chromatin (Wilson et al. 2013). Moreover, we reported previously that the proteasome is required to negatively regulate mRNA levels of genes containing a DSB (Pankotai et al. 2012). However, it was unclear whether the proteasome is required to remove RNAPII from chromatin following the induction of DSBs. To examine this, we monitored the levels of phospho-RPB1 (S2, S5, and S7) in chromatin-enriched extracts from cells that were treated with neocarzinostatin in either the presence or absence of proteasome inhibitor MG-132. DSBs triggered a rapid and strong decrease of phospho-RPB1 (S2, S5, and S7) levels on chromatin (Supplemental Fig. S6A, left panel), in agreement with our previous work (Pankotai 
A

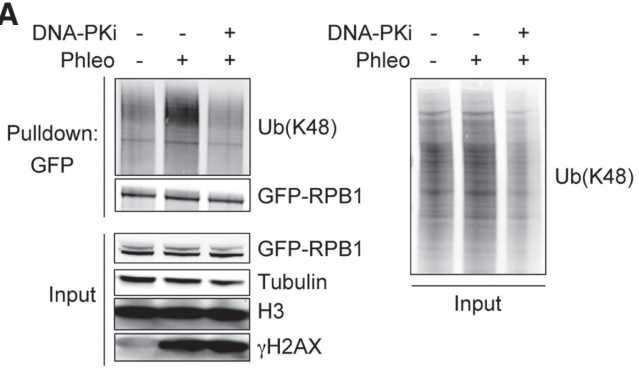

C
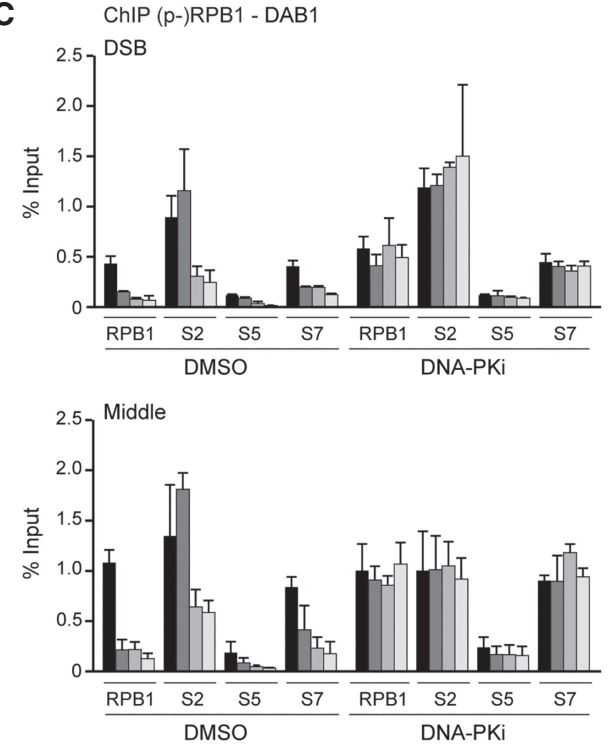

D $\quad$ ChIP (p-)RPB1 - SLCO5a1
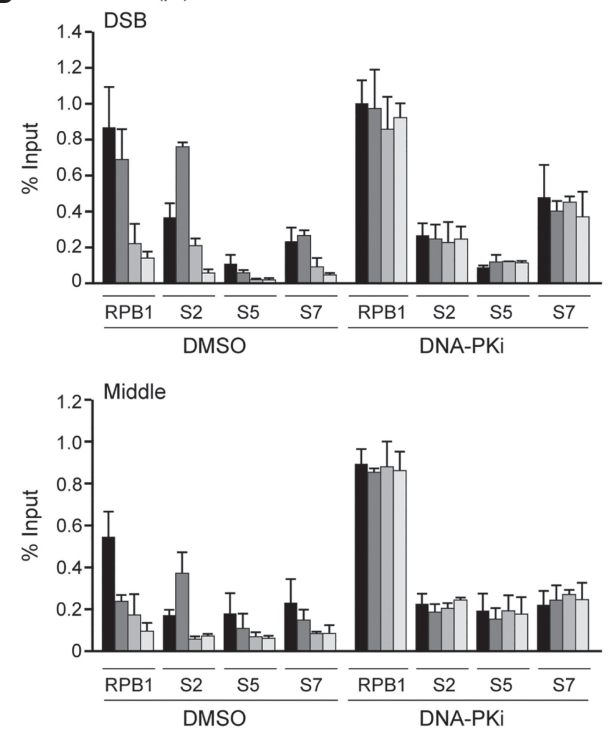

B
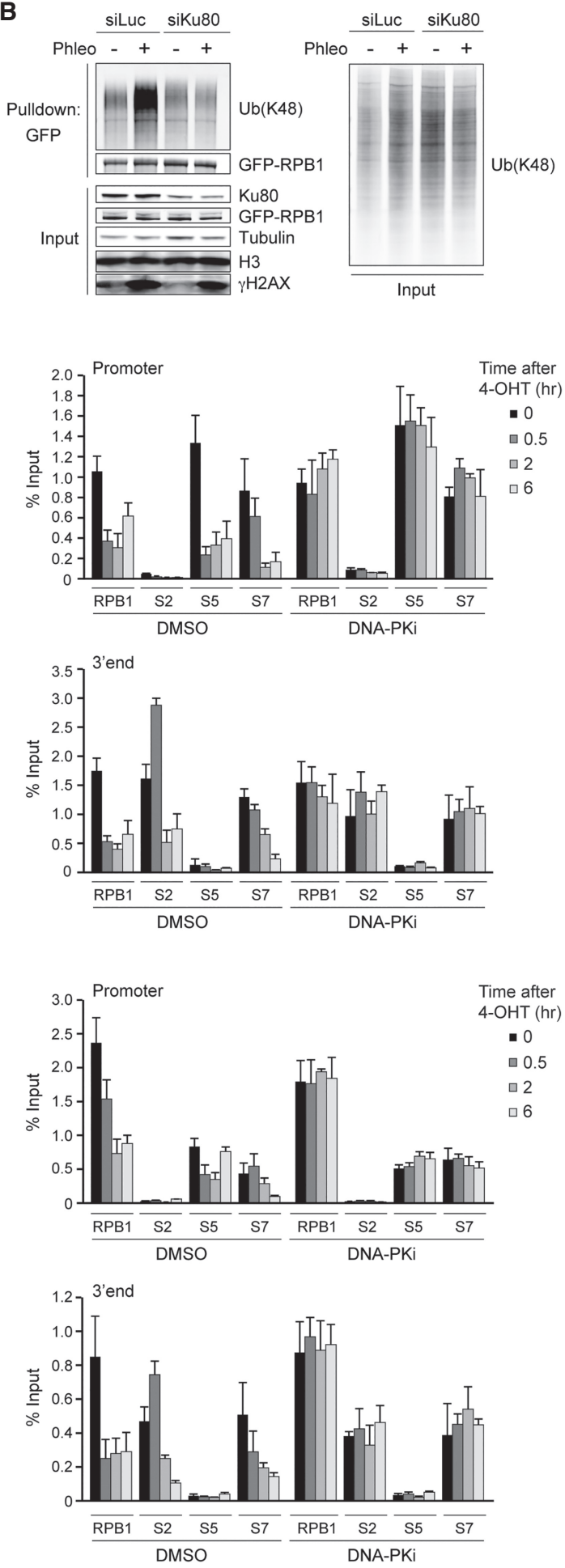

Figure 4. DNA-PK affects the ubiquitylation and occupancy of RPB1. (A) Pull-downs of GFP-RPB1 under denaturing conditions in phleomycin (Phleo)- and DNA-PK inhibitor (DNA-PKi)-treated U2OS cells. Cells were also treated with proteasome inhibitor (MG-132) 25 min before the phleomycin treatment. Blots were probed for $\mathrm{Ub}(\mathrm{K} 48), \mathrm{GFP}, \mathrm{H} 3$, and $\gamma \mathrm{H} 2 \mathrm{AX}$. Tubulin was used as a loading control. (B) As in $A$, except that cells were transfected with the indicated siRNA. (C) ChIP-qPCR against RPB1 and S2-, S5-, or S7-phosphorylated RPB1 (p-RPB1) in DMSO-treated (control) and DNA-PKi-treated U2OS HA-ER-I-PpoI cells at the indicated time points after 4-OHT treatment and at the indicated positions at $D A B 1$. A representative experiment is shown. A repeat of the experiment is shown in Supplemental Figures S10A and S11A. (D) ChIP-qPCR against RPB1 and S2-, S5-, or S7-phosphorylated RPB1 (p-RPB1) in DMSO-treated (control) and DNAPKi-treated U2OS HA-ER-I-PpoI cells at the indicated time points after 4-OHT treatment and at the indicated positions at SLCO5a1. A representative experiment is shown. A repeat of the experiment is shown in Supplemental Figures S10B and S11B. 
et al. 2012). In addition, we found that MG-132-mediated proteasome inhibition abolished this effect (Supplemental Fig. S6A, right panel). Similarly, DNA-PK inhibition also impaired phospho-RPB1 release from damaged chromatin (Supplemental Fig. S5D), which is consistent with our finding that DNA-PK activity is required to evict phospho-RPB1 from genes following DSB induction by the IPpoI nuclease (Fig. 4C,D). Together, these findings suggest a role for the proteasome in the release of $\mathrm{RPB} 1$ from genes containing DSBs.

Such a scenario would imply a role for the proteasome directly at DSBs. Indeed, proteasome components have been shown to be recruited to DSBs in yeast (Krogan et al. 2004) and to sites of laser-induced DNA damage in human cells (Galanty et al. 2012). However, whether the proteasome acts at bona fide DSBs in human cells remained unclear. We therefore monitored the levels of the proteasome subcomplexes $19 S$ and 20 S at I-PpoI-induced DSBs in the DAB1 and SLCO5a1 genes by ChIP. Both proteasome subcomplexes accumulated near the DSBs and along the entire broken gene, reaching maximum levels mostly at $\sim 2 \mathrm{~h}$ after damage induction (Fig. 5A-H; Supplemental Figs. S13A,B, S14A,B). Proteasome levels did not increase on transcribed genes flanking DAB1 (OMA1 and PRKAA2) (Supplemental Figs. S6B,C, S13C, S14C), indicating that proteasome accumulation at DAB1 and SLCO5a1 is dependent on DSB induction. Finally, we found that DNAPK inhibition or WWP2 depletion abolished the recruitment of these proteasome components to DSBs in these actively transcribed genes (Fig. 5A-H; Supplemental Figs. S13A,B, S14A,B). These findings demonstrate that DNAPK and WWP2 trigger recruitment of the proteasome to DSBs in actively transcribed genes to promote eviction of RNAPII by acting on ubiquitylated RPB1.

WWP2 promotes the accumulation of core NHEJ factors at DNA damage

We showed that WWP2 promotes both NHEJ and RPB1 ubiquitylation at DSBs. However, it is not clear how WWP2 affects NHEJ and how this is linked to its role in RPB1 ubiquitylation. NHEJ relies on the binding and retention of the heterodimer Ku70/Ku80 at DSB ends, which allows for the recruitment and activation of DNA-PKcs. This in turn recruits the XRCC4/LigIV complex, which ultimately seals the break (Blackford and Jackson 2017). To assess how WWP2 affects NHEJ, we first determined the contribution of WWP2 to the accumulation of XRCC4 and $\mathrm{Ku} 80$ at DSBs inflicted by UV-A laser microirradiation. Indeed, depletion of WWP2 significantly reduced the recruitment of both core NHEJ proteins (Fig. 6A,B), while DNA damage induction was comparable, as monitored by the accumulation of the DSB sensor protein NBS1 (Supplemental Fig. S7A-C). To confirm this finding, we performed chromatin-binding assays to measure the association of NHEJ factors with damaged chromatin following exposure of cells to phleomycin. We observed a strong accumulation of NHEJ factors $1 \mathrm{~h}$ after phleomycin treatment in the histone H3-enriched chromatin fraction (Supplemental Fig. S7D,E). Again, we found that depletion of WWP2 strongly impaired the recruitment of both Ku70 and XRCC4 to damaged chromatin (Supplemental Fig. S7D,E). Finally, we also found that IR-induced phosphoDNA-PKcs (S2056), but not $\gamma \mathrm{H} 2 \mathrm{AX}$, focus formation is strongly impaired after WWP2 depletion (Fig. 6C; Supplemental Fig. S7F-H). Collectively, these findings demonstrate that WWP2 promotes the efficient assembly of NHEJ factors at DSBs, thereby stimulating efficient DNA repair.

The C-terminal domain (CTD) of RPB1 is ubiquitylated in response to DSBs to promote NHEJ

We next investigated how the role of WWP2 in recruiting NHEJ factors may be linked to its impact on RBP1 ubiquitylation and the subsequent eviction of RNAPII during transcription repression at DSBs. To this end, we first examined which residues in RPB1 could contribute to its ubiquitylation by WWP2 following DSB induction. Studies in mice suggested that WWP2 targets RPB1 on eight lysines that reside in the nonconsensus sequence of its CTD (Li et al. 2007). However, those observations did not exclude the possibility that WWP2 may ubiquitylate RPB1 by targeting one or several of the other 97 lysine residues distributed along the protein. To resolve this issue, we used mouse NIH3T3 cell lines stably expressing a-amanitin-resistant wild-type GFP-RPB1 (8K) or mutant GFP-RPB1 (OK) in which the eight lysine residues in the nonconsensus sequence of the CTD were substituted with serine residues (Dias et al. 2015). Similar to wildtype human GFP-RPB1 (Fig. 6D), wild-type mouse GFP-RPB1 (8K) becomes ubiquitylated in response to DSBs induced by phleomycin treatment, while inhibition of DNA-PK impaired K48-linked ubiquitylation of mRPB1 (Fig. 6E). Importantly, however, we did not observe an increase in DSB-induced ubiquitylation of mutant mRPB1 (OK) (Fig. 6D,E). Reciprocal pull-downs using TUBEs confirmed that wild-type mRPB1 (8K), but not mutant mRPB1 (OK), was ubiquitylated following DSB induction (Supplemental Fig. S7I). This indicates that the ubiquitylation of RPB1 induced by DSBs occurs mainly, if not solely, on the lysines in the CTD nonconsensus sequence. Most notably, we found that wild-type and mutant mRPB1 interact equally efficiently with WWP2 (Supplemental Fig. S7J), suggesting that the eight lysine substitutions in the CTD of RPB1 do not affect its ubiquitylation by impairing the interaction with WWP2. Rather, RPB1 ubiquitylation is abrogated because WWP2's target sites for ubiquitylation are absent.

To assess whether the role of WWP2 in promoting NHEJ involves its function in ubiquitylating RPB1, we monitored the accumulation of XRCC4 at DSBs exposed to UV-A laser microirradiation. We found that the accumulation of XRCC4 at sites of laser-induced DNA damage was impaired in cells expressing mutant $(\mathrm{OK})$ versus wild-type (8K) GFP-RPB1 (Fig. 6F). We also examined p-DNA-PKcs (S2056) focus formation in these cells. A clear induction of focus formation of p-DNA-PKcs in IRexposed cells expressing wild-type (8K) GFP-RPB1 (Fig. 6G) was observed. However, focus formation of p-DNA- 

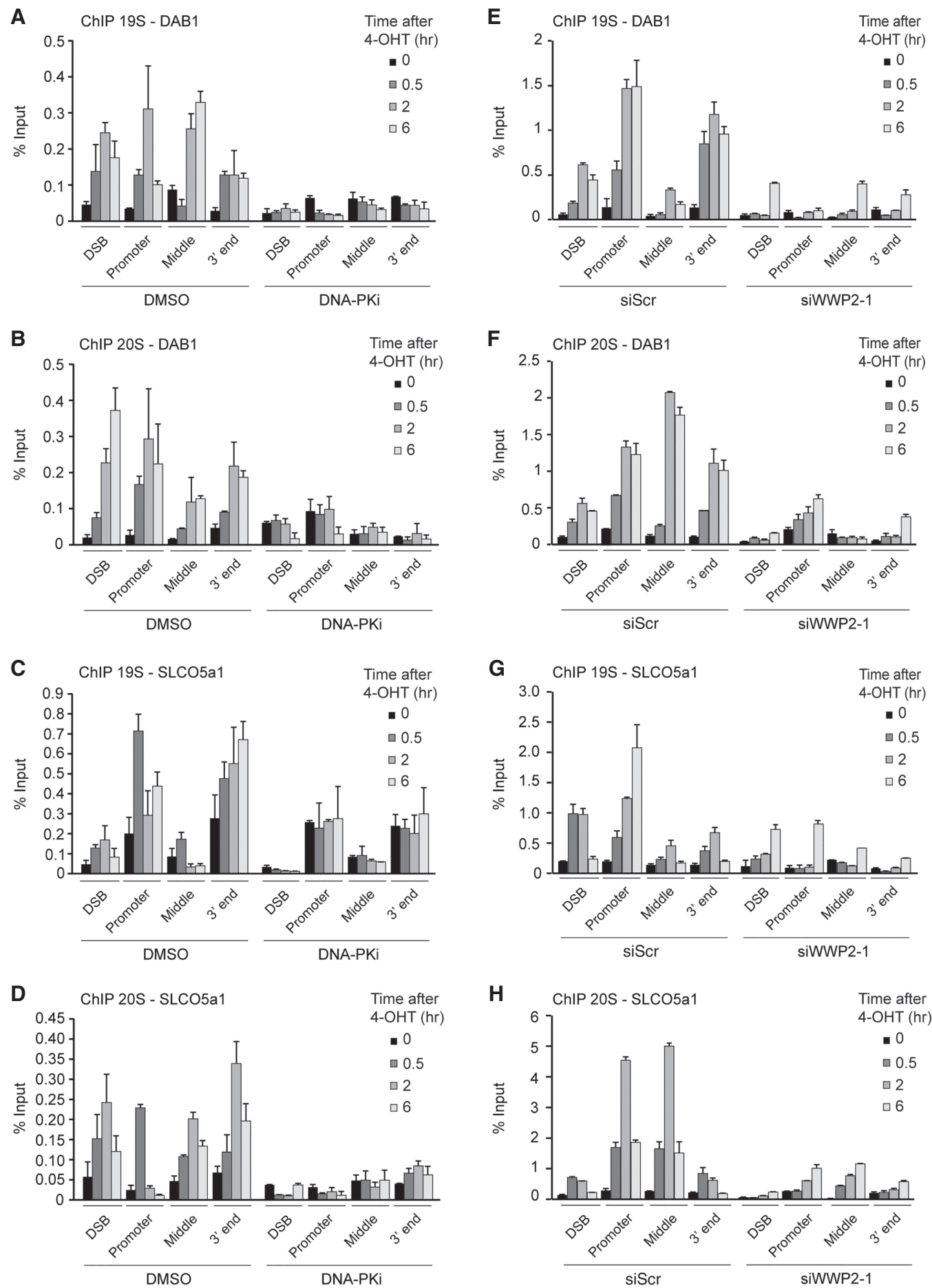

Figure 5. Proteasomes are recruited to broken genes in a DNA-PKcs- and WWP2-dependent manner. $(A)$ ChIP-qPCR against the $19 \mathrm{~S}$ proteasome in DMSO-treated (control) and DNA-PKi-treated U2OS HA-ER-I-PpoI cells at the indicated time points after 4-OHT treatment and at the indicated positions at $D A B 1$. The mean \pm SD from qPCR replicates of a representative experiment is shown. A repeat of the experiment is shown in Supplemental Figure S13A. (B) As in $A$, except that the 20S proteasome was examined. A repeat of the experiment is shown in Supplemental Figure S13A. (C) As in A, except for SLCO5a1. A repeat of the experiment is shown in Supplemental Figure S13B. (D) As in B, except for SLCO5a1. A repeat of the experiment is shown in Supplemental Figure S13B. $(E)$ ChIP-qPCR against the 19S proteasome in U2OS HA-ER-I-PpoI cells transfected with the indicated siRNA at the indicated time points after 4-OHT treatment and at the indicated positions at $D A B 1$. The mean $\pm \mathrm{SD}$ from qPCR replicates of a representative experiment is shown. A repeat of the experiment is shown in Supplemental Figure S14A. $(F)$ As in E, except that the 20S proteasome was examined. A repeat of the experiment is shown in Supplemental Figure S14A. $(G)$ As in E, except for SLCO5a1. A repeat of the experiment is shown in Supplemental Figure S14B. (H) As in F, except for SLCO5a1. A repeat of the experiment is shown in Supplemental Figure S14B. 
A
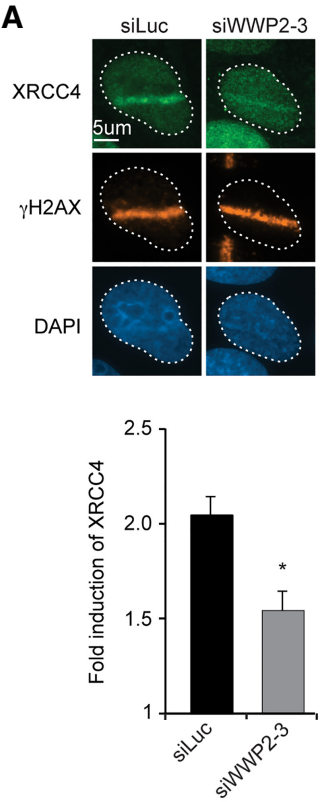

D

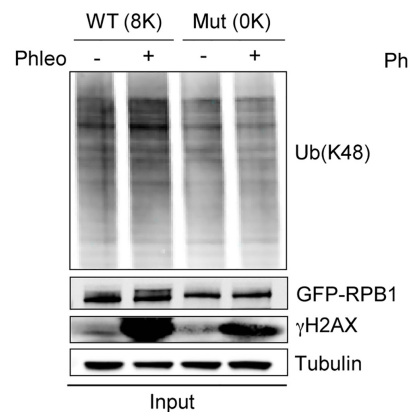

F

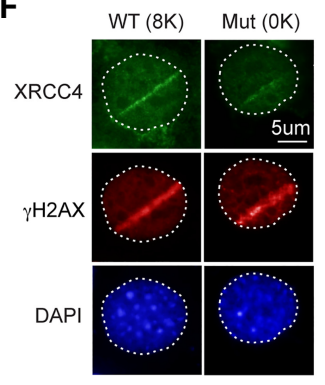

B
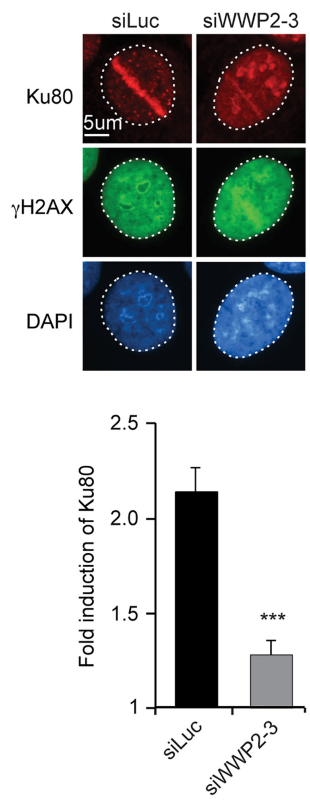

$\frac{\mathrm{WT}(8 \mathrm{~K})}{+} \frac{\text { Mut }(\mathrm{OK})}{-+}$

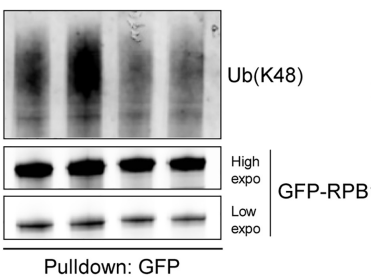

C
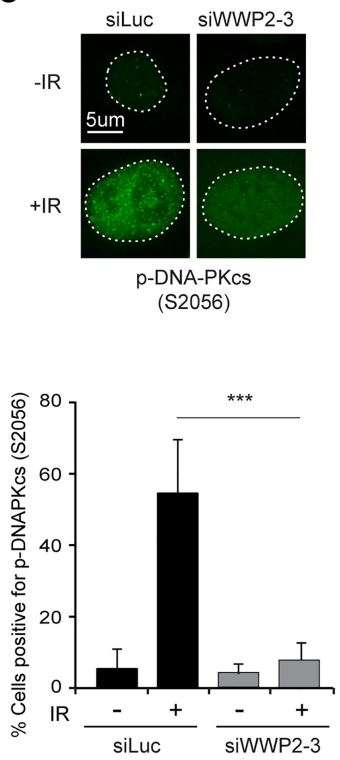

E

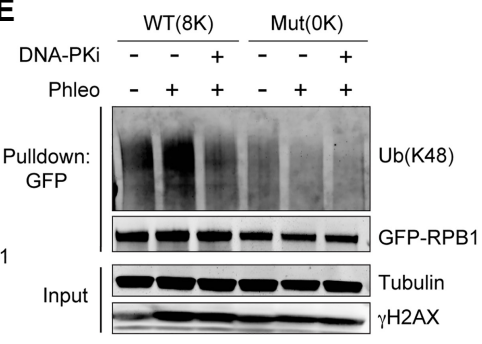

G

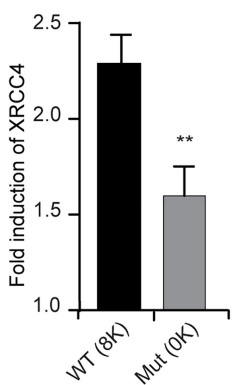

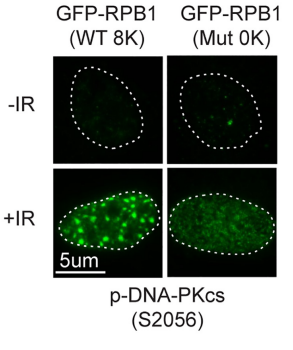

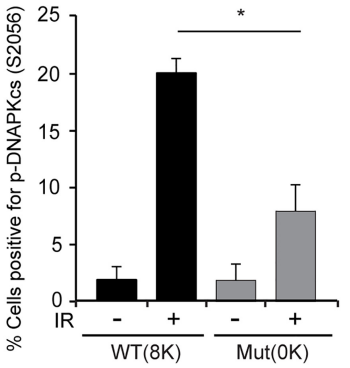

Figure 6. WWP2-dependent RPB1 ubiquitylation promotes accumulation of NHEJ factors at DSBs. (A) Immunofluorescence (IF) images (top panel) and quantification (bottom panel) of XRCC4 recruitment to DNA damage tracks generated by UV-A laser microirradiation in U2OS cells transfected with the indicated siRNAs. $\gamma \mathrm{H} 2 \mathrm{AX}$ was used as a DNA damage marker. The mean $\pm \mathrm{SD}$ from three independent experiments is shown. Statistical significance was calculated using the Student's $t$-test. $\left({ }^{*}\right) P<0.05$. $(B)$ As in $A$, except for Ku80. The mean \pm SD from six independent experiments is shown. Statistical significance was calculated using the Student's $t$-test. $\left({ }^{* * *}\right) P<0.001$. $(C) \mathrm{IF}$ images (top panel) and quantification (bottom panel) of p-DNA-PKcs (S2056) focus formation $1 \mathrm{~h} \mathrm{after} 10$ Gy of IR in U2OS cells transfected with the indicated siRNAs. The mean \pm S.E.M from four independent experiments is shown. Statistical significance was calculated using the Student's $t$-test. $\left({ }^{* *}\right) P<0.001$. (D) Pull-downs of GFP-RPB1 wild type $(8 \mathrm{~K})$ or mutant $(0 \mathrm{~K})$ under denaturing conditions in untreated and phleomycin (Phleo)-treated NIH3T3 cells. Cells were also treated with proteasome inhibitor (MG-132) 25 min before the phleomycin treatment. Blots were probed for $\mathrm{Ub}(\mathrm{K} 48)$, GFP, and $\gamma \mathrm{H} 2 \mathrm{AX}$. Tubulin was used as a loading control. $(E)$ As in $D$, except that cells were also treated with DNA-PKi. (F) IF images (left panel) and quantification (right panel) of XRCC4 recruitment to DNA damage tracks generated by UV-A laser microirradiation in NIH3T3 cells expressing wild-type (8K) or mutant (0K) GFP-RPB1. The mean \pm SEM from three independent experiments is shown. Statistical significance was calculated using the Student's $t$-test. $\left.{ }^{* *}\right) P<0.01$. $(G)$ IF images (left panel) and quantification (right panel) of p-DNA-PKcs (S2056) focus formation $1 \mathrm{~h}$ after 10 Gy of IR in NIH3T3 cells expressing wild-type $(8 \mathrm{~K})$ or mutant $(\mathrm{OK})$ GFP-RPB1. The mean \pm SEM from three independent experiments is shown. Statistical significance was calculated using the Student's $t$-test. $\left(^{*}\right) P<0.05$. 
PKcs was dramatically reduced in IR-exposed cells expressing mutant (OK) GFP-RPB1. Thus, our results suggest that DSB-induced ubiquitylation of RPB1 occurs mainly within its CTD. This further promotes DNA-PK activation and, subsequently, the retention of downstream NHEJ factors, the latter of which involves the eviction of RNAPII to prevent transcription-dependent clearance of NHEJ proteins at DSB sites (Fig. 7).

\section{Discussion}

In this study, we provide insight into the molecular events that lead to transcription silencing induced by DSBs at RNAPII transcribed genes. The repression of transcription occurs via K48-linked ubiquitylation of the CTD of the RNAPII subunit RPB1. This process is regulated by the DNA-PK complex and its effector, the HECT E3 ubiquitin ligase WWP2. Moreover, it leads to RNAPII degradation directly on damaged chromatin through recruitment of the proteasome. Both WWP2 and the ubiquitylation of RPB1's CTD are important for the proper retention of core NHEJ factors at DSBs. We propose that removal of RNAPII from DSBs at transcribed genes protects the NHEJ machinery from collision with the transcription

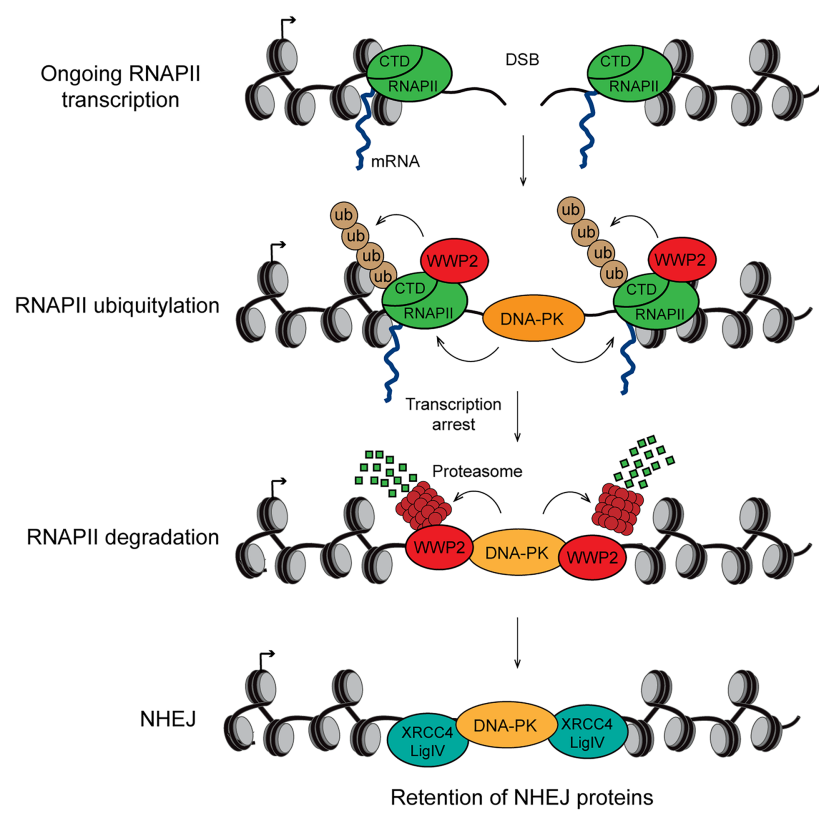

Figure 7. Model of how DNA-PK/WWP2-dependent transcription silencing at DSBs promotes NHEJ. DNA-PK and the HECT E3 ubiquitin ligase WWP2 are recruited to a DSB in a gene that is actively transcribed by RNAPII. DNA-PK effectuates WWP2dependent K48-linked ubiquitylation of the CTD of RNAPII subunit RPB1 and the subsequent recruitment of the proteasome. The proteasome triggers RNAPII degradation directly on damaged chromatin, thereby silencing transcription of the broken gene. Finally, transcriptional silencing prevents the loss of DNA-PK and downstream NHEJ factors from DSBs, likely by protecting the NHEJ machinery from collision with the transcription machinery, thereby promoting efficient DSB repair via NHEJ. machinery. This in turn prevents the loss of activated DNA-PK and downstream NHEJ factors from DSBs, thereby promoting efficient DSB repair via NHEJ (Fig. 7).

\section{WWP2 promotes cNHEJ}

E3 ubiquitin ligases can be classified into three groups: the RING ligases, the cullin-RING ligases, and the HECT ligases. Several RING ligases have been shown to play a crucial role in regulating DSB repair. For instance, RNF8 and RNF138 regulate Ku70/Ku80 ubiquitylation in G1 and S/G2, respectively (Feng and Chen 2012; Ismail et al. 2015). In addition, cullin-RING ligase activity was also shown to drive this process, although the identity of the ligase involved is unknown (Brown et al. 2015). Ubiquitylated $\mathrm{Ku} 70 / \mathrm{Ku} 80$ is then removed from chromatin in a VCP-dependent manner and targeted for degradation by the proteasome (van den Boom et al. 2016). This allows for completion of NHEJ (Ishida et al. 2017) or activation of end resection, thereby triggering the alternative DSB repair pathway of HR (Ismail et al. 2015; van den Boom et al. 2016). The FBXW7-associated cullin-RING ligase, on the other hand, regulates the recruitment of XRCC4 to DSB sites through its K63-linked ubiquitylation (Zhang et al. 2016). This stimulates the interaction between XRCC4 and $\mathrm{Ku} 70 / \mathrm{Ku} 80$ to promote efficient NHEJ. Finally, histones in DSB-flanking chromatin are subject to ubiquitylation. DSBs activate ATM, which leads to the recruitment of two RING ligases-RNF8 and RING1bthat monoubiquitylate H2AK119 (Shanbhag et al. 2010; Kakarougkas et al. 2014; Ui et al. 2015). This histone mark is required to silence transcription of DSB-flanking genes and is thought to promote DSB repair via cNHEJ by promoting the efficient recruitment or retention of Ku70/Ku80 at DNA breaks (Kakarougkas et al. 2014; Ui et al. 2015).

While it is evident that RING and cullin-RING ligase play crucial roles in regulating NHEJ, the role of HECT ligases in this DNA repair process remained unclear. Here, we provide several lines of evidence supporting a direct role for the HECT E3 ubiquitin ligase WWP2 in cNHEJ factors. First, we demonstrated that WWP2 is recruited to sites of DNA damage inflicted by laser microirradiation as well as to bona fide nuclease-induced DSBs. Second, the loss of WWP2 impaired the association of core NHEJ such as $\mathrm{Ku} 70, \mathrm{Ku} 80$, and XRCC4 as well as the activation of DNA-PK at DNA breaks. Third, the depletion of WWP2 dramatically impaired NHEJ in EJ5-GFP assays and random plasmid integration assays as well as at I-PpoI-induced DSBs in RNAPII transcribed genes. Fourth, WWP2 protected cells against IR-induced DSBs, which are predominantly repaired by NHEJ. Together, these findings suggest that the HECT E3 ubiquitin ligase WWP2 is an important player in the cNHEJ repair pathway of DSB repair.

\section{WWP2 targets RNAPII for cNHEJ}

How does WWP2 regulate cNHEJ? Several observations suggested that WWP2 regulates this repair process by 
targeting RNAPII. First, we identified 11 of the 12 RNAPII subunits as WWP2-interacting proteins by pull-down coupled to MS. Importantly, the largest RNAPII subunit, RPB1, which plays a pivotal role in transcription regulation, appeared to be a strong interactor of WWP2. Second, we found that DSBs lead to a clear increase in the K48linked ubiquitylation of RPB1 in a manner dependent on DNA-PK and its effector, WWP2. Intriguingly, this modification occurs on the lysine residues that reside in the nonconsensus sequences of the CTD, which is critical for RPB1's role in transcription regulation. Third, functional analysis of these lysines revealed that their DSBinduced ubiquitylation by WWP2 is important to promote DNA-PK activation during cNHEJ. Given that WWP2 also promotes efficient accrual of $\mathrm{Ku} 70 / \mathrm{Ku} 80$ and XRCC4 at DNA breaks, our observations strongly suggest that WWP2 promotes NHEJ by regulating RPB1 ubiquitylation following DSB induction. However, the fact that DNAPKcs activity is required for RBP1 ubiquitylation and its removal from damaged chromatin may indicate that WWP2 is not involved in the initial recruitment of the NHEJ machinery to DNA breaks but rather promotes its stabilization at these lesions by clearing out the RNAPII machinery. Moreover, we cannot rule out the possibility that WWP2 also ubiquitylates other components of the cNHEJ machinery to regulate DSB repair. In addition, WWP2 may also target components of DNA repair pathways other than cNHEJ, potentially broadening its regulatory function in the DNA damage response. Future work will be required to unravel how widespread WWP2's role in this response is.

\section{WWP2 promotes transcription silencing of broken genes}

What is the role of WWP2-mediated RPB1 ubiquitylation in transcription regulation at DSBs? We found that WWP2 promotes transcriptional silencing at sites of DNA damage induced by laser microirradiation as well as at bona fide DSBs induced at RNAPII transcribed genes. Our work suggests that this process strongly depends on the WWP2-mediated ubiquitylation of RPB1. First, this posttranslational modification triggered the proteasomedependent eviction of RNAPII from DSB sites. Second, this local RNAPII eviction led to loss of transcription. Thus, WWP2 promotes transcription silencing following DSB induction at RNAPII transcribed genes by regulating RPB1 ubiquitylation and its local eviction. However, we observed that RNAPII eviction and transcription repression were mostly delayed and not completely abrogated in the absence of WWP2, suggesting the existence of alternative mechanisms potentially involving other E3 ubiquitin ligases that may cooperate with WWP2 to promote efficient transcriptional silencing at DSBs.

\section{WWP2-dependent transcription silencing and cNHEJ}

How does WWP2-dependent transcription silencing of broken genes affect their repair by NHEJ? It has been shown that in response to DSBs, transcriptional elonga- tion factor ENL (MLLT1) is phosphorylated by ATM (Ui et al. 2015; Ui and Yasui 2016). This phosphorylation enhances the interaction between ENL and PRC1 and enforces accrual of PRC1 at transcription elongation sites near DSBs, leading to transcriptional repression via PRC1-mediated ubiquitylation of histone H2A. Strikingly, both ENL and PRC1 are also necessary for the accumulation of $\mathrm{Ku} 70$ at DSBs near active transcription sites, suggesting a functional interplay between transcription repression and cNHEJ (Ui et al. 2015; Ui and Yasui 2016). Indeed, we observed that DNA-PK and WWP2 activities are required to repress transcription elongation when DSBs arise in actively transcribed genes, thereby also preserving the association of NHEJ factors with broken ends. These findings may suggest a scenario in which transcription silencing prevents direct collision between the elongating RNAPII machinery and the NHEJ machinery at DNA breaks, thereby preventing its early loss from DNA lesions and promoting efficient cNHEJ.

\section{Cross-talk of DNA-PK and WWP2 during transcription silencing of broken genes}

We reported previously that transcription arrest in response to DSBs in RNAPII transcribed genes is regulated by DNA-PK activity (Pankotai et al. 2012; Pankotai and Soutoglou 2013). Here we demonstrate that DNA-PK activity triggers this process by promoting (1) WWP2-dependent K48-linked ubiquitylation of RPB1, (2) recruitment of the proteasome to broken genes, and (3) proteasomedependent release of RPB1 from broken genes. However, while DNA-PK binding is restricted to DSB ends, we found that WWP2, RBP1, and the proteasome spread across DSB-containing genes. This raises the question of how DNA-PK can trigger a WWP2- and proteasomedependent release of RBP1 across broken genes. A possibility is that a yet-to-be-identified protein becomes phosphorylated and activated by DNA-PK and signals to WWP2 to trigger ubiquitylation and proteasome-dependent release of RPB1. Future work may therefore focus on uncovering the identity and mode of action of this protein to increase our understanding of how DNA-PK- and WWP2-dependent transcriptional silencing at broken genes is orchestrated.

\section{DNA-PK- and WWP2-dependent transcription silencing is unique to broken genes}

DSBs that arise in a gene that is actively transcribed by RNAPII lead to a DNA-PK- and WWP2-dependent arrest of transcription elongation. This process, which remained unaffected by ATM inhibition (Pankotai et al. 2012), is mediated by the ubiquitylation and eviction of RNAPII. In contrast, DSBs generated in close proximity to a gene lead to its transient repression through ATM- or PARP-1-mediated chromatin remodeling, which induces a chromatin context that is repressive for transcription (Shanbhag et al. 2010; Kakarougkas et al. 2014; Gong et al. 2015, 2017; Ui et al. 2015; Ui and Yasui 2016; Awwad et al. 2017; Abu-Zhayia et al. 2018; Gong and Miller 2018). 
This process, which was not affected by DNA-PK inhibition (Shanbhag et al. 2010), relies on the recruitment and activities of PRC1 and negative transcription factor NELF, which negatively impacted phospho-RPB1 (S2 and S5) levels but not that of unmodified RPB1 (Chou et al. 2010; Shanbhag et al. 2010; Polo et al. 2012; Awwad et al. 2017). Thus, ATM- and PARP1-dependent transcription silencing, in contrast to that regulated by DNA-PK and WWP2, may not involve RNAPII eviction and relies largely on a transient arrest of elongating RNAPII induced by chromatin remodeling and negative regulators of transcription elongation. Moreover, it suggests that two distinct mechanisms exist for the silencing of transcription when DSBs occur either within or in close proximity to an actively transcribed gene, relying on DNA-PK/WWP2 and ATM/PARP, respectively. A better understanding of the context in which the DNA-PK-, ATM-, and PARP1dependent signaling pathways are activated will help to further clarify potential cross-talk between DNA-PK-, ATM-, and PARP1-mediated silencing at DNA breaks. Moreover, transcription can also be initiated from DSB sites to produce DNA damage-induced RNAs (ddRNAs) that regulate the DNA damage response (Ohle et al. 2016; Michelini et al. 2017). It will be of interest to unravel how the interplay between DNA-PK-, ATM-, and PARP1mediated transcription silencing and transcription of ddRNAs is orchestrated at DSBs.

\section{Material and methods}

Cell culture

U2OS, HeLa GFP-Ku80 (a kind gift from D. van Gent), U2OS GFP-WWP2, U2OS GFP-RPB1, and U2OS-pEP15 cells were maintained in DMEM (Dulbecco's modified Eagle's medium) supplemented with $10 \%$ FBS (fetal bovine serum) and antibiotics. NIH3T3 GFP-RPB1 cells (a kind gift from A. Pombo) were maintained in DMEM GlutaMAX-I (Gibco) and HEPES (Gibco) supplemented with $10 \%$ FBS and antibiotics. All cell lines were cultured in $5 \% \mathrm{CO}_{2}$ at $37^{\circ} \mathrm{C}$.

Generation of stable cell lines

U2OS-pEP15 cells were generated by cotransfection of U2OS cells with pWHE1-146 and pWHE1-320-HA-ER-I-PpoI plasmids (Lemaitre et al. 2014). pWHE1-320-HA-ER-I-PpoI was generated by cloning HA-ER-PpoI, which was obtained as an EcoRI fragment from pBABE-Puro-HA-ER-I-PpoI (Pankotai et al. 2012), into EcoRI-digested PWHE1-320. pWHE1-146 allowed for expression of the reverse tetracycline-controlled transcription activator (rtTA), which, upon Dox addition, can bind the tet operator in pWHE1-320-HA-ER-I-PpoI to drive expression of HA-ER-I-PpoI. Stable clones were selected by $1000 \mu \mathrm{g} / \mathrm{mL}$ G418 (Sigma-Aldrich) resistance and analyzed by immunostaining of HA-I-PpoI and $\gamma \mathrm{H} 2 \mathrm{AX}$ after Dox and 4-hydroxytamoxifen (4-OHT) treatment.

U2OS cells stably expressing GFP-tagged WWP2 were generated by transfection of U2OS cells with pEGFP-C1-WWP2-IRESPuro plasmid. This plasmid was generated by cloning WWP2 cDNA, which was obtained as a BglII/EcoRI fragment from pDEST-WWP2, into BglII/EcoRI-digested pEGFP-C1-IRES-Puro. Stable clones were selected by $1 \mu \mathrm{g} / \mathrm{mL}$ puromycin resistance and subjected to Western blot analysis for GFP-WWP2 expression.
U2OS cells stably expressing $\alpha$-amanitin-resistant EYFP-tagged RPB1 were generated by transfection of U2OS cells with the pYFP-RPB1aAMR plasmid (75284 from Addgene; originally from Roger Stinger). Thirty-six hours after transfection, the cells were incubated in the presence of $2 \mu \mathrm{g} / \mathrm{mL} \alpha$-amanitin (Sigma) for 4-5 d. Individual clones were selected by $500 \mu \mathrm{g} / \mathrm{mL}$ G418 (Sigma-Aldrich) resistance and subjected to Western blot analysis for EYFP-RPB1 expression.

\section{SiRNA and plasmid transfections}

Cells were transfected with siRNAs (Table 1) using RNAiMAX (Invitrogen) according to the manufacturer's instructions. Typically, cells were transfected twice with siRNAs at 0 and $24 \mathrm{~h}$ at a concentration of $20 \mathrm{nM}$. After $24 \mathrm{~h}$, the medium was replaced by DMEM GlutaMAX-I (Gibco) supplemented with 10\% FBS and antibiotics, and cells were used for further experiments. Cells were transfected with plasmid DNA using Lipofectamine 2000 (Invitrogen) or JetPEI (Polyplus) according to the manufacturer's instructions. Cells were typically analyzed $24 \mathrm{~h}$ after transfection.

\section{Preparation of MS samples}

For SILAC labeling, U2OS cells expressing WWP2-GFP or GFP-NLS were cultured for $14 \mathrm{~d}$ in medium containing "heavy" (H)- and "light" (L)-labeled forms of the amino acids arginine and lysine, respectively. SILAC-labeled WWP2-GFP (H) or GFPNLS (L) cells were lysed in EBC buffer $150 \mathrm{mM}$ Tris at $\mathrm{pH} 7.5$, $150 \mathrm{mM} \mathrm{NaCl}, 0.5 \% \mathrm{NP}-40,2.5 \mathrm{mM} \mathrm{MgCl}_{2}$, protease inhibitor cocktail [Roche]) in the presence of $500 \mathrm{U}$ of benzonase. Lysates were subjected to pull-down using GFP-Trap-A beads (Chromotek). The beads were subsequently washed twice with EBC-300 buffer and twice with $50 \mathrm{mM}\left(\mathrm{NH}_{4}\right)_{2} \mathrm{CO}_{3}$ followed by overnight digestion using $2.5 \mu \mathrm{g}$ of trypsin at $37^{\circ} \mathrm{C}$ under constant shaking. Peptides of the WWP2-GFP (H) or GFP-NLS (L) precipitates were mixed in a 1:1 ratio and desalted using a Sep-Pak tC18 cartridge by washing with $0.1 \%$ acetic acid. Finally, peptides were eluted with $0.1 \%$ acetic acid and $60 \%$ acetonitrile and lyophilized.

MS analysis

MS was performed essentially as described previously (Schimmel et al. 2014). Samples were analyzed in technical duplicates on a Q-Exactive Orbitrap mass spectrometer (Thermo Scientific) coupled to an EASY-nanoLC 1000 system (Proxeon, Odense). Digested peptides were separated using a $13-\mathrm{cm}$ fused silica capillary

Table 1. siRNAs

\begin{tabular}{ll}
\hline Target & \multicolumn{1}{c}{ Sequence $\left(5^{\prime}-3^{\prime}\right)$} \\
\hline $\begin{array}{l}\text { Luciferase (Luc) } \\
\text { Scramble (Scr) }\end{array}$ & $\begin{array}{l}\text { CGUACGCGGAAUACUUCGA } \\
\text { ON-TARGETplus nontargeting pool } \\
\text { (Dharmacon) }\end{array}$ \\
DNA-PKcs-S & $\begin{array}{l}\text { ON-TARGETplus SMARTpool (Dharmacon) } \\
\text { DNA-PKcs }\end{array}$ \\
Ku 80 & CAAGAUGGUGGCCAUGGAG \\
XRCC4 & AUAUGUUGGUGAUGCUUUAGU \\
LigIV & GCACAAAGAUGGAGAUGUA \\
WWP2-1 & UGACAAAGUUGGCAAGGAA \\
WWP2-2 & GAUUCCUCUACCAGUCUUC \\
WWP2-3 & CAGGAUGGGAGAUGAAAUA \\
RNF8 & GAGGGCCAAUGGACAAUUA \\
CHD4 & GAGCGGCAGUUCUUUGUGAUU \\
\hline
\end{tabular}


(ID: $75 \mu \mathrm{m}$, OD: $375 \mu \mathrm{m}$; Polymicro Technologies) packed inhouse with 1.8- $\mu \mathrm{m} \mathrm{C18}$ beads (Reprospher; Dr. Maisch, Ammerburch-Entringen). Peptides were separated by liquid chromatography using a gradient of $2 \%$ to $95 \%$ acetonitrile with $0.1 \%$ formic acid at a flow rate of $200 \mathrm{~nL} / \mathrm{min}$ for $2 \mathrm{~h}$. The mass spectrometer was operated in positive-ion mode at $2.2 \mathrm{kV}$ with the capillary heated to $200^{\circ} \mathrm{C}$. Data-dependent acquisition mode was used to automatically switch between full-scan MS and tandem MS (MS/MS) scans, using a top 10 method. Full-scan MS spectra were obtained with a resolution of 70,000 , a target value of $3 \times$ $10^{6}$, and a scan range from 400 to $2000 \mathrm{~m} / \mathrm{z}$. Higher collisional dissociation (HCD) MS/MS was recorded with a resolution of 17,500 , a target value of $1 \times 10^{5}$, and a normalized collision energy of $25 \%$. The precursor ion masses selected for MS/MS analysis were subsequently dynamically excluded from MS/MS analysis for $60 \mathrm{sec}$. Precursor ions with a charge state of 1 and $>6$ were excluded from triggering MS/MS events. Raw MS files were analyzed with the MaxQuant software suite (version 1.45.5.1; Max Planck Institute of Biochemistry). The data have been deposited to the ProteomeXchange Consortium via the PRIDE (Proteomics Identifications) partner repository with the data set identifier PXD012606.

\section{Chemicals}

Cells were treated with phleomycin (InvivoGen) at the indicated concentrations for $1 \mathrm{~h}$ and collected for further analysis. Cells were treated with neocarzinostatin (Sigma-Aldrich) at a final concentration of $250 \mathrm{ng} / \mathrm{mL}$ for $15 \mathrm{~min}$, washed, fixed, and harvested at the indicated time points after treatment. For multiphoton laser microirradiation, cells were exposed to DRB (Sigma-Aldrich), which was dissolved in DMSO, for $6 \mathrm{~h}$ at a final concentration of $100 \mu \mathrm{M}$. For chromatin fractionation experiments, cells were exposed to the proteasome inhibitor MG-132 (Tocris Bioscience) for $1 \mathrm{~h}$ at a final concentration of $20 \mu \mathrm{M}$, whereas for RPB1 ubiquitylation assays, cells were exposed to MG-132 (Sigma-Aldrich) for $85 \mathrm{~min}$ at a final concentration of $5 \mu \mathrm{M}$. For the analysis of p-RPB1 (S2) ubiquitylation, cells were exposed for $1 \mathrm{~h}$ to the broad-spectrum inhibitor of deubiquitylating enzymes PR169 (LifeSensors, SI9619), which was dissolved in DMSO and used at a final concentration of $20 \mu \mathrm{M}$. DNA-PKcs inhibitor (NU7026; Millipore) was dissolved in methanol and used at a final concentration of $10 \mu \mathrm{M}$ in RPB1 ubiquitylation assays. DNAPKcs inhibitor (NU7026; Sigma-Aldrich) was dissolved in DMSO and used at a $20 \mu \mathrm{M}$ final concentration for ChIP and chromatin fractionation experiments.

\section{Generation of DSBs by IR}

IR was delivered to U2OS and NIH3T3 cells by an YXlon X-ray generator machine $(200 \mathrm{kV}$; $4 \mathrm{~mA}$; dose rate $1 \mathrm{~Gy} / \mathrm{min})$.

\section{UV-A laser microirradiation}

U2OS cells were grown on 18-mm coverslips and sensitized with 10 MM 5'-bromo-2-deoxyuridine (BrdU) for $24 \mathrm{~h}$ as described (Luijsterburg et al. 2016). For microirradiation, the cells were placed in a Chamlide TC-A live-cell imaging chamber that was mounted on the stage of a Leica DM IRBE wide-field microscope stand (Leica) integrated with a pulsed nitrogen laser (Micropoint Ablation Laser System; Andor). The pulsed nitrogen laser $(16 \mathrm{~Hz}$, $364 \mathrm{~nm}$ ) was directly coupled to the epifluorescence path of the microscope and focused through a Leica $40 \times$ HCX plan apo $1.25-0.75$ oil immersion objective. The growth medium was replaced by $\mathrm{CO}_{2}$-independent Leibovitz's L15 medium supple- mented with 10\% FCS and penicillin-streptomycin (Invitrogen), and cells were kept at $37^{\circ} \mathrm{C}$. The laser output power was set to $72-$ 78 to generate strictly localized subnuclear DNA damage. Following microirradiation, cells were incubated for the indicated time points at $37^{\circ} \mathrm{C}$ in Leibovitz's L15 and subsequently fixed with $4 \%$ formaldehyde before immunostaining. Cells were microirradiated (two iterations per pixel) within 7-10 min using Andor IQ software (Andor).

\section{Multiphoton laser microirradiation}

U2OS and NIH3T3 cells were grown on 18-mm coverslips and placed in a Chamlide $\mathrm{CMB}$ magnetic chamber with $\mathrm{CO}_{2}$-independent Leibovitz's L15 medium supplemented with 10\% FCS and penicillin-streptomycin (Invitrogen). Laser microirradiation was carried out on a Leica SP5 confocal microscope equipped with an environmental chamber set to $37^{\circ} \mathrm{C}$. DSB-containing tracks (1.5- $\mu \mathrm{m}$ width) were generated with a Mira mode locked titanium-sapphire (Ti:sapphire) laser $(1=800 \mathrm{~nm}$; pulse length $=$ $200 \mathrm{fs}$; repetition rate $=76 \mathrm{MHz}$; output power $=80 \mathrm{~mW}$ ) using a UV-transmitting $63 \times$ HCX plan apo 1.4 NA oil immersion objective (Leica). Confocal images were recorded before and after laser irradiation at 5 - or 10 -sec time intervals over a period of 3-5 min.

\section{EJ5-GFP reporter assay}

HEK293 cell lines containing a stably integrated copy of the EJ5GFP reporter were used to measure the repair of I-SceI-induced DSBs by NHEJ (Bennardo et al. 2008). Briefly, $48 \mathrm{~h}$ after siRNA transfection, cells were cotransfected with a mCherry expression vector and the I-SceI expression vector pCBASce. Forty-eight hours later, the percentage of GFP-positive cells among mCherry-positive cells was determined by FACS on a BD LSRII flow cytometer (BD Bioscience) using FACSDiva software version 5.0.3. Quantifications were performed using WinMDI 2.9 (freeware), FACSDiva (BD Biosciences), or FlowJo software (Flowing Software 5.2.1.).

\section{Random plasmid integration assay}

U2OS cells were seeded (day 1) and transfected with siRNAs the following day (day 2). At the end of day 2, the cells were transfected with $2 \mu \mathrm{g}$ of gel-purified BamHI-EcoRI-linearized pEGFP-C1 plasmid. The cells were subsequently transfected twice with siRNAs at 24 and $36 \mathrm{~h}$ after the first transfection (day 3 and day 4, respectively). On day 5, cells were collected, counted, seeded, and grown in medium without or with $0.5 \mathrm{mg} / \mathrm{mL}$ G418. The transfection efficiency was determined on the same day by FACS analysis. The cells were incubated at $37^{\circ} \mathrm{C}$ to allow colony formation, and the medium was refreshed on days 8 and 12 . On day 15 , the cells were washed with $0.9 \% \mathrm{NaCl}$ and stained with methylene blue. Colonies of $>50$ cells were scored. Random plasmid integration efficiency was scored as the number of G418-resistant colonies normalized by the plating efficiency, which was determined by the number of colonies formed on plates without G418.

\section{Immunofluorescence (IF)}

U2OS and NIH3T3 cells were grown on glass coverslips in a 12-well plate, rinsed three times with PBS (phosphate-buffered saline), and fixed on the coverslips with $4 \%$ formaldehyde for $12 \mathrm{~min}$. Next, the cells were rinsed three times with PBS, permeabilized with $0.5 \%$ Triton for $5 \mathrm{~min}$, and then rinsed again three 
times with PBS. Subsequently, 3\% PBS-BSA (bovine serum albu$\mathrm{min}$ ) was added to the cells for $30 \mathrm{~min}$, after which the solution was removed, and a solution of $3 \%$ PBS-BSA with primary antibodies was added (Table 2). After incubation for $2 \mathrm{~h}$ or overnight, the cover slips were washed four times with $3 \%$ PBS-BSA, and a solution of $3 \%$ PBS-BSA with secondary antibodies was added. Next, coverslips were placed in the dark. After $2 \mathrm{~h}$, cells were rinsed three times with PBS, and a solution of PBS-DAPI (4',6-diamidino-2-phenylindole) was added to the cells. Ten minutes later, the solution was removed by washing three times with PBS. Next, a drop of Aqua-Polymont was placed on a microscope slide, and the coverslip was placed on top of it. Images were taken with a Zeiss AxioImager D2 wide-field fluorescence microscope equipped with a 40.63 and $100 \times$ plan apo (1.4 NA) oil immersion objective, an HXP 120 metal-halide lamp for excitation, and Zen 2012 software. ImageJ software was used for image analysis.
ChIP after I-PpoI-induced DSBs

U2OS cells stably expressing HA-ER-I-PpoI (U2OS-pEP15) were transfected with siRNAs (Table 1) at a concentration of $25 \mathrm{nM}$ using RNAiMAX (Invitrogen) according to the manufacturer's instructions. After $24 \mathrm{~h}$, the medium was replaced by DMEM GlutaMAX-I (Gibco) supplemented with $10 \%$ FBS and antibiotics, and cells were used for further experiments. After $36 \mathrm{~h}$ of transfection, cells were treated with $1 \mu \mathrm{g} / \mathrm{mL}$ Dox (Sigma-Aldrich) for $12 \mathrm{~h}$, and then 4-OHT (Sigma-Aldrich) was added at a $2 \mu \mathrm{M}$ final concentration to induce nuclear translocation of HA-ER-I-PpoI. Cells were harvested at different time points up to $6 \mathrm{~h}$ after 4-OHT addition. DNA-PK inhibitor (NU7026; Sigma and Millipore) was added $1 \mathrm{~h}$ prior the addition of 4-OHT. ChIP was performed as described with few modifications (Pankotai et al. 2012). Briefly, one $150-\mathrm{mm}$ dish with $50 \%$ confluent cells was used for each time point. The cells were cross-linked for

Table 2. Antibodies

\begin{tabular}{|c|c|c|c|c|c|}
\hline Protein & Host & Obtained from & ChIP & IF & Western blot \\
\hline \multicolumn{6}{|l|}{ Primary antibodies } \\
\hline WWP2 & Rabbit & Bethyl Laboratories, Inc. (A302-935A) & $2 \mu \mathrm{g}$ & & $1: 2000$ \\
\hline GFP & Mouse & Roche (11814460001) & & & $\begin{array}{l}1: 1000 \\
1: 2000\end{array}$ \\
\hline$\gamma \mathrm{H} 2 \mathrm{AX}$ & Mouse & Millipore JBW301 (05-636) & & $1: 1000$ & $1: 2000$ \\
\hline 53BP1 & Rabbit & Novus (NB100-304) & & $1: 1000$ & \\
\hline $\mathrm{Ku} 70$ & Mouse & Santa Cruz Biotechnology (sc-17789) & & & $1: 500$ \\
\hline Tubulin $(\alpha)$ & Mouse & Sigma T6199 (clone DM1A) & & & $\begin{array}{l}1: 2000 \\
1: 5000\end{array}$ \\
\hline XRCC4 & Rabbit & Abcam (ab145) & & & $1: 1000$ \\
\hline $\mathrm{XRCC} 4$ & Rabbit & D. van Gent & & $1: 1000$ & \\
\hline H3 & Rabbit & Abcam (ab1791) & & & $1: 5000$ \\
\hline ATM & Rabbit & Cell Signaling (2873S; D2E2) & & & $1: 1000$ \\
\hline Ku80 & Rabbit & Santa Cruz Biotechnology (H-300; sc-9034) & & $1: 500$ & $1: 500$ \\
\hline RPB1 & Mouse & Santa Cruz Biotechnology (A-10; sc-17798) & & & $\begin{array}{l}1: 300 \\
1: 500\end{array}$ \\
\hline Ubiquitin Lys48 & Rabbit & Millipore (Apu2 05-1307) & & & $\begin{array}{l}1: 1000 \\
1: 2000\end{array}$ \\
\hline FK2 & Mouse & ENZO Life Sciences (BML-PW8810-0500) & & & $\begin{array}{l}1: 1000 \\
1: 2000\end{array}$ \\
\hline XRCC4 & Rabbit & D. van Gent & & $1: 500$ & \\
\hline p-DNA-PKcs (S2056) & Rabbit & Abcam (ab18192) & & $\begin{array}{l}1: 500 \\
1: 750\end{array}$ & $\begin{array}{l}1: 500 \\
1: 750\end{array}$ \\
\hline DNA-PKcs & Mouse & Abcam (ab1832) & & & $\begin{array}{l}1: 500 \\
1: 750\end{array}$ \\
\hline LigIV & Rabbit & Abcam (ab80514) & & & $1: 1000$ \\
\hline RPB1 S2 & Rabbit & Abcam (ab5095) & $2 \mu \mathrm{g}$ & & \\
\hline RPB1 S5 & Rabbit & Abcam (ab5131) & $2 \mu \mathrm{g}$ & & \\
\hline RPB1 S7 & Rat & D. Eick & $2 \mu \mathrm{g}$ & & \\
\hline $\mathrm{RPB} 1$ & Mouse & Santa Cruz Biotechnology (N20) & $2 \mu \mathrm{g}$ & & \\
\hline H3 & Rabbit & Abcam (ab1791) & & & $1: 5000$ \\
\hline $\mathrm{H} 4$ & Rabbit & Abcam (ab10158) & & & $1: 1000$ \\
\hline PSMD4 (proteasome 19S) & Rabbit & Abcam (ab20239) & $2 \mu \mathrm{g}$ & & \\
\hline Proteasome $20 \mathrm{~S} \alpha+\beta$ & Rabbit & Abcam (ab22673) & $2 \mu \mathrm{g}$ & & \\
\hline PARP1 & Rabbit & Cell Signaling (9542S) & & & $1: 1000$ \\
\hline NEDD4 & Rabbit & Cell Signaling (2740S) & & & $1: 1000$ \\
\hline RPB2 & Rabbit & Novus (NBP2 - 20207) & & & $1: 1000$ \\
\hline \multicolumn{6}{|l|}{ Secondary antibodies } \\
\hline Goat $\alpha$-mouse (770) & & Biotium & & & $1: 10.000$ \\
\hline Goat $\alpha$-rabbit IgG $(680)$ & & Biotium & & & $1: 10.000$ \\
\hline Goat $\alpha$-mouse + Alexa 555 & & Invitrogen & & $1: 1000$ & \\
\hline Goat $a$-rabbit + Alexa 488 & & Invitrogen & & $1: 1000$ & \\
\hline
\end{tabular}


$10 \mathrm{~min}$ in $0.75 \%(\mathrm{v} / \mathrm{v})$ paraformaldehyde (Electron Microscopy Sciences) and then sonicated in sonication buffer $(50 \mathrm{mM}$ HEPES at $\mathrm{pH} 8,140 \mathrm{mM} \mathrm{NaCl}, 1 \mathrm{mM}$ EDTA, $1 \%$ [v/v] Triton X-100, $1 \%$ [v/v] SDS, protease inhibitor cocktail [Roche]). Twenty-five milligrams of chromatin was diluted 10 times with RIPA buffer (50 mM Tris- $\mathrm{HCl}$ at $\mathrm{pH} 8,150 \mathrm{mM} \mathrm{NaCl}, 1 \mathrm{mM}$ EDTA, 1\% [v/ v] Triton X-100, 0.1\% [w/v] Na-deoxycholate, 0/1\% [v/v] SDS) and subjected to immunoprecipitation using $2 \mu \mathrm{g}$ of antibody (Table 2) and $30 \mu \mathrm{L}$ of $\left(\sim 10^{7}\right)$ Dynabeads M-280 (Invitrogen). The beads were washed once for $10 \mathrm{~min}$ with low-salt buffer $(20 \mathrm{mM}$ Tris- $\mathrm{HCl}$ at $\mathrm{pH} 8,150 \mathrm{mM} \mathrm{NaCl}, 2 \mathrm{mM}$ EDTA, $1 \%$ [v/v] Triton $\mathrm{X}-100,0.1 \%[\mathrm{v} / \mathrm{v}] \mathrm{SDS})$, once for $10 \mathrm{~min}$ with high-salt buffer (20 mM Tris- $\mathrm{HCl}$ at $\mathrm{pH} 8,500 \mathrm{mM} \mathrm{NaCl}, 2 \mathrm{mM}$ EDTA, 1\% [v/ v] Triton X-100, 0.1\% [v/v] SDS), once for 10 min with wash buffer (10 mM Tris- $\mathrm{HCl}$ at pH 8, $250 \mathrm{mM} \mathrm{LiCl}, 1 \mathrm{mM}$ EDTA, $1 \%$ [v/v] NP-40, 1\% [w/v] Na-deoxycholate), and twice for $10 \mathrm{~min}$ each with TE buffer. The elution was done twice for $15 \mathrm{~min}$ at $65^{\circ} \mathrm{C}$. Cross-links were reversed by incubation for $6 \mathrm{~h}$ at $65^{\circ} \mathrm{C}$. The DNA was purified after Proteinase K and RNase A treatment using phenol-chloroform extraction and resuspended in $50 \mu \mathrm{L}$ of TE buffer. The enrichment in each experiment was calculated using the formula (immunoprecipitation sample-IgG control)/input. Each value represents a relative DNA concentration calculated by the Ct values of samples with known DNA concentrations, which were used to generate a standard curve for absolute linear quantification.

\section{RT-qPCR-based mRNA analysis}

Total cellular RNA was purified from U2OS HA-ER-I-PpoI cells using the RNeasy total RNA purification kit (Qiagen) according to the manufacturer's instructions. cDNA was synthesized with an RT-PCR kit (Qiagen) according to the manufacturer's instructions in a final volume of $10 \mu \mathrm{L}$. RT-qPCR analysis was performed using $10 \mathrm{ng}$ of total RNA as a template and 1 pmol of each primer (Table 3). Reactions were carried out using a Roche LightCycler 480 II system for 50 cycles. The purity of the PCR products was determined by melting curve analysis. Each value represents a relative DNA concentration calculated by the Ct values of samples with known DNA concentrations, which were used to generate a standard curve for absolute linear quantification. For each condition, mRNA values were determined, and each sample was normalized to cyclophilin B (PPIB) mRNA levels.

\section{qPCR-based analysis of I-PpoI-induced DSBs}

Genomic DNA was purified from U2OS HA-ER-I-PpoI cells using a DNeasy blood and tissue purification kit (Qiagen) according to the manufacturer's instructions. qPCR analysis was performed in a final volume of $10 \mu \mathrm{L}$ using $10 \mathrm{ng}$ of genomic DNA as a template and 1 pmol of each primer (Table 3). Reactions were carried out using a Roche LightCycler 480 II system for 50 cycles. The purity of the PCR products was determined by melting curve analysis. Cutting efficiency was calculated by measuring the uncut DNA fraction by qPCR using primers spanning the I-PpoI recognition site and comparing that with the amplification of a part of the gene lacking such a site.

\section{Monitoring nascent transcription at DNA damage sites}

Nascent transcription was monitored by 5 -EU labeling of nascent RNA with $1 \mathrm{mM} 5$-EU, which was added $5 \mathrm{~min}$ after UV-A or multiphoton laser microirradiation. 5-EU incorporation was determined $1 \mathrm{~h}$ later by using a Click-it RNA imaging kit (Invitrogen) as described previously (Gong et al. 2015).
Table 3. Primers

\begin{tabular}{|c|c|}
\hline RT-qPCR & Sequence $\left(5^{\prime}-3^{\prime}\right)$ \\
\hline SLCO5al forward & GCCCTGCAGTGGGATATTTA \\
\hline SLCO5al reverse & CAATGGCACAAAGGAGGAAT \\
\hline DAB1 forward & AGCCGCTAGGAGTGAGCAT \\
\hline DAB1 reverse & CTCAGCCСТCTCGACTCATC \\
\hline RYR2 forward & AAGCCСТCTCGTCTGAAACA \\
\hline RYR2 reverse & CCACCCAGACATTAGCAGGT \\
\hline PPIB forward & CTTCCCCGATGAGAACTTCAAACT \\
\hline PPIB reverse & САССТССАТGСССТСТАGAАСТTТ \\
\hline I-PpoI cleavage & Sequence $\left(5^{\prime}-3^{\prime}\right)$ \\
\hline SLCO5al cut forward & CСАTTCATCTCСТTGССTGT \\
\hline SLCO5al cut reverse & TAGGGACAGTGGGAATCTCG \\
\hline SLCO5al control forward & CTGTTGAGAGCTCCССТACG \\
\hline SLCO5al control reverse & CCAGAAGCCCATAGCAAGAG \\
\hline DAB1 cut forward & ACCATACGTGGCAGAGTGTG \\
\hline DAB1 cut reverse & AGGCAGGCAGGCATCTTAT \\
\hline RYR2 cut forward & TCATCCATTCATGAACGTCAC \\
\hline RYR2 cut reverse & GAGCCATGGAAGTCAGAATGA \\
\hline ChIP-qPCR & Sequence $\left(5^{\prime}-3^{\prime}\right)$ \\
\hline SLCO5al promoter forward & TGGCTTATGGGACACGTACA \\
\hline SLCO5al promoter reverse & GCCTGACAGCCAATAAAAGC \\
\hline SLCO5al middle forward & AGAGATGAGGGAAGGGGAAA \\
\hline SLCO5al middle reverse & GGAGCTGGGAGTCAGAACAG \\
\hline $\begin{array}{l}\text { SLCO5al cut }-1 \mathrm{~kb} \\
\text { forward }\end{array}$ & CCCAGCACTCACAATTTTCC \\
\hline SLCO5al cut $-1 \mathrm{~kb}$ reverse & ATGGTCAATGCCAGCTCTTT \\
\hline SLCO5al cut $+1 \mathrm{~kb}$ forward & GGAACAGAACAGAGCCCTCA \\
\hline SLCO5al cut + $1 \mathrm{~kb}$ reverse & CTAGCCAGTTTTCCCAGCAC \\
\hline SLCO5al $3^{\prime}$ forward & GAGGGCTGGATACCTCAACA \\
\hline SLCO5al 3' reverse & GTAGGGGAGCATGAGCTTTG \\
\hline DAB1 promoter forward & TTGTGGGGTGTGCATAACAT \\
\hline DAB1 promoter reverse & GTGCTGCCTCTAGGGTCTTG \\
\hline DAB 1 cut $-1 \mathrm{~kb}$ forward & AACCGACCAGTGTTTTCCTG \\
\hline DAB 1 cut $-1 \mathrm{~kb}$ reverse & CTGGCGCTCAGAGAGAAGTT \\
\hline DAB 1 cut $+1 \mathrm{~kb}$ forward & TGAATCTTGGGGATCTCAGC \\
\hline DAB 1 cut $+1 \mathrm{~kb}$ reverse & TGATCTCACTCAACCCACCA \\
\hline DAB1 middle forward & CGСTTCСТTСССТTAАТTCC \\
\hline DAB1 middle reverse & GTGCTGAGGAGCCTGTTACC \\
\hline DAB1 $3^{\prime}$ forward & TGAGGGTGAACCCCAAGTAG \\
\hline DAB1 $3^{\prime}$ reverse & СТCCTGGCTCСTTGTCACTC \\
\hline PRKAA2 forward & TCATGCTACCAGCCACAGAG \\
\hline PRKAA2 reverse & CACGGTCCACCAAACTTTCT \\
\hline OMA1 forward & CTGAATATGGGAGGGGGATT \\
\hline OMA1 reverse & AAACCTAGGTGGAGCCCAGT \\
\hline CDKN1A (p21) forward & CCGAAGTCAGTTCCTTGTGG \\
\hline CDKN1A (p21) reverse & CGCTCTCTCACCTCСТCTGA \\
\hline INTS4 forward & ACCCAAAAGTGGAATTGCTG \\
\hline INTS4 reverse & ATGATGGAAATCGCTTCTGG \\
\hline
\end{tabular}

\section{TUBE assay}

TUBE assays were performed according to the manufacturer's instructions (LifeSensors, UM401 and UM402), except that cells were collected from plates prior to cell lysis, and cell lysates were treated with $0.25 \mathrm{U} / \mu \mathrm{L}$ benzonase for $1 \mathrm{~h}$ at $4^{\circ} \mathrm{C}$ under constant mixing.

\section{GFP pull-down under denaturing conditions}

For each immunoprecipitation, $2 \times 10^{6}$ to $15 \times 10^{6}$ cells were collected and resuspended in $200 \mu \mathrm{L}$ of lysis buffer $(20 \mathrm{mM}$ Tris/CI at $\mathrm{pH} 7.5,50 \mathrm{mM} \mathrm{NaCI}, 0.5 \%$ IGEPAL, $1 \%$ sodium deoxycholat, $1 \%$ SDS, $5 \mathrm{mM} \mathrm{MgCl}_{2}$, protease inhibitor cocktail [Roche]). Next, $800 \mu \mathrm{L}$ of wash buffer was added $(20 \mathrm{mM}$ Tris at $\mathrm{pH} 7.5,50 \mathrm{mM}$ $\mathrm{NaCI}, 0.5 \%$ IGEPAL, $0.5 \%$ sodium deoxycholate, $0.5 \%$ SDS, 
Protease inhibitor cocktail tablets) with $0.25 \mathrm{U} / \mu \mathrm{L}$ benzonase (final concentration), and samples were incubated for $60 \mathrm{~min}$ at room temperature. Cell lysates were centrifuged at 15,000g for $10 \mathrm{~min}$ at room temperature. Fifty microliters of cell lysate (input) was collected in a separate tube and mixed with $2 \times$ Laemmli buffer. The remaining cell lysate was added to $25 \mu \mathrm{L}$ of GFPTrap-A beads (Chromotek) and incubated under constant mixing conditions for $2 \mathrm{~h}$ at room temperature. Beads were washed six times with $1000 \mu \mathrm{L}$ of wash buffer. Twenty-five microliters of $2 \times$ Laemmli buffer was added to the beads, and samples were boiled for $10 \mathrm{~min}$. After brief centrifugation at full speed, samples were separated from the beads and subjected to Western blot analysis.

\section{GFP pull-down under physiological conditions}

For each immunoprecipitation reaction, a cell pellet $\left(2 \times 10^{6}\right.$ to $15 \times 10^{6}$ cells) was resuspended in $1000 \mu \mathrm{L}$ of EBC buffer $(50 \mathrm{mM}$ Tris at $\mathrm{pH} 7.5,150 \mathrm{mM} \mathrm{NaCl}, 0.5 \%$ NP-40, $2.5 \mathrm{mM} \mathrm{MgCl}_{2}$, Protease inhibitor cocktail tablets), and $0.25 \mathrm{U} / \mu \mathrm{L}$ benzonase was added. Samples were incubated for $60 \mathrm{~min}$ at $4^{\circ} \mathrm{C}$ under constant mixing. The cell lysate was centrifuged at $15,000 \mathrm{~g}$ for $10 \mathrm{~min}$ at room temperature. Fifty microliters of cell lysate (input) was collected in a separate tube and mixed with $2 \times$ Laemmli buffer. Twenty-five microliters of prewashed GFP-Trap-A beads (Chromotek) was added to the remaining cell lysate and incubated under constant mixing conditions for $2 \mathrm{~h}$ or overnight at $4^{\circ} \mathrm{C}$ and then washed five times with the EBC buffer with the $\mathrm{NaCl}$ concentration adjusted to $250 \mathrm{mM}$. Twenty-five microliters of $2 \times$ Laemmli buffer was added to the beads and boiled for $10 \mathrm{~min}$. After brief centrifugation at full speed, samples were separated from the beads and subjected to Western-blot analysis.

\section{Western blot analysis}

Cells were lysed in $2 \times$ Laemmli buffer, and proteins were separated by SDS-PAGE for $3-4 \mathrm{~h}$ at $75 \mathrm{~V}$ using $4 \%-12 \%$ precast polyacrylamide gels (Bio-Rad) and 20x MOPS running buffer (Invitrogen). Next, proteins were transferred onto nitrocellulose membranes (Millipore) for $2 \mathrm{~h}$ at $52 \mathrm{~V}$. The membrane was probed with primary antibodies for $2 \mathrm{~h}$ or overnight and washed three times with $0.1 \%$ PBS-Tween 20 followed by incubation with secondary antibodies for $2 \mathrm{~h}$ (Table 3). Membranes were scanned and analyzed using a Licor Odyssey scanner (LI-COR Biosciences).

\section{Chromatin fractionation}

Cells were collected in PBS complemented with PIC (Roche). The pellets were collected by centrifugation and then resuspended in hypotonic buffer (10 mM Tris- $\mathrm{HCl}$ at $\mathrm{pH} 8.0,1.5 \mathrm{mM} \mathrm{MgCl}_{2}, 10$ $\mathrm{mM} \mathrm{KCl}, 1 \times \mathrm{PIC})$, and homogenized with a loose dounce homogenizer. Next, cells were supplemented with sucrose buffer (20 mM Tris- $\mathrm{HCl}$ at $\mathrm{pH} 8.0,15 \mathrm{mM} \mathrm{KCl}, 60 \mathrm{mM} \mathrm{NaCl}$, $0.34 \mathrm{mM}$ sucrose [Sigma-Aldrich], $0.15 \mathrm{mM}$ spermine [Sigma-Aldrich], $0.5 \mathrm{mM}$ spermidine [Sigma-Aldrich], $1 \times$ PIC). The supernatant or cytoplamic extract was collected. The pellet was resuspended in sucrose buffer supplemented with high-salt buffer (20 mM Tris- $\mathrm{HCl}$ at $\mathrm{pH} 8.0,25 \%$ glycerol [Fermentas], $1.5 \mathrm{mM}$ $\mathrm{MgCl}_{2}, 0.2 \mathrm{mM}$ EDTA, $900 \mathrm{mM} \mathrm{NaCl}, 1 \times \mathrm{PIC}$ ) and incubated for $30 \mathrm{~min}$ on ice. The supernatant or nuclear extract was collected. The pellet was resuspended in sucrose buffer, sonicated with Diagenode Bioruptor (Diagenode), and used as the chromatin fraction.

\section{Chromatin-binding assay}

The chromatin-binding assay after phleomycin treatment was based on a previously published protocol (Britton et al. 2013) and used with modifications. Briefly, 150,000 U2OS cells were grown per 6-cm dish for $24 \mathrm{~h}$ and then transfected with siRNAs. Next, the cells were treated with $500 \mu \mathrm{M}$ phleomycin for $1 \mathrm{~h}$, washed three times with PBS, and incubated in extraction buffer (RNase A, 0.7\% Triton X-100 in CSK buffer. RNase A was added just prior to use to prevent inactivation by Triton. After $3 \mathrm{~min}$ of incubation, samples were taken for the chromatin-unbound fraction and mixed with the same amount of $2 \times$ Laemmli buffer. Cells were subjected to a second extraction, washed with PBS, lysed, and incubated in Laemmli buffer with benzonase for 15 min to obtain the chromatin-bound fraction. Samples were heated for $7 \mathrm{~min}$ at $90^{\circ} \mathrm{C}$ and subjected to Western blot analysis.

\section{Clonogenic survival assay}

Cells were transfected with siRNA (see above), seeded in 10-cm dishes $(2000,4000$, or 6000 cells per plate) and exposed to different doses of IR. Eight days later, the cells were washed with $0.9 \% \mathrm{NaCl}$ and stained with $2.5 \mathrm{~g} / \mathrm{L}$ methylene blue in $5 \%$ ethanol (Sigma-Aldrich). Colonies consisting of $>50$ cells were counted as positive.

\section{Acknowledgments}

We thank Dirk Eick for providing antibodies raised against S7P RNAPII antibody, and Dik van Gent for HeLa cells expressing GFP-Ku80 and XRCC4 antibody. We are grateful to Ana Pombo for the mouse NIH3T3 cells expressing GFP-RPB1 (8K and 0K). We thank Kyle Miller, Steve Jackson, and Kristijan Ramadan for sharing protocols, and Alex Pines for help with setting up the SILAC-labeled MS experiments. This work was funded by an EMBO fellowship grant (ALTF 815-2013) to P.C.; a National Research, Development, and Innovation Office grant (NKFIH; GINOP-2.3.2-15-2016-00020) and a European Research Council (ERC)-16-Mobil grant (ERC-16-M-127752) to T.P.; a Federation of European Biochemical Societies fellowship, a Leiden University Medical Center research fellowship, and a Netherlands Organization for Scientific Research (NWO) VENI grant to M.S.L.; an ERC Starting grant (decoding SUMO, 310913) to A.C.O.V.; an ERC Consolidator grant (3D repair, 2017-22), an Institut National du Cancer (INCA) grant (2015-113), and an ANR-10-LABX-0030INRT fund, which is a French state fund managed by the Agence Nationale de la Recherche under the frame program Investissements d'Avenir (ANR-10-IDEX-0002-02), to E.S.; and an ERC Consolidator grant (chromatin repair code, 50364) and a grant from Leiden University (Research Profile Bioscience: The Science Base of Health) to H.v.A.

Author contributions: P.C. generated U2OS cells stably expressing GFP-tagged RPB1 and performed GFP and TUBE pull-downs, IR-induced focus analysis, laser microirradiation, Western blot analysis, and chromatin-binding assays; analyzed the SILAC-based MS experiments; and wrote the paper. T.P. performed ChIP experiments, qPCR-based repair assays, RT-qPCRbased expression analysis, chromatin fractionation assays, TUBE pull-downs, and Western blot analysis and wrote the paper. W.W.W. performed clonogenic survival and plasmid integration assays and assisted with laser microirradiation experiments. M.A.X.T. performed laser microirradiation experiments to study WWP2 recruitment. A.F. assisted in the chromatin fractionation experiments as well as the siRNA transfections and DNA purifications during ChIP experiments. C.B. assisted in constructing 
the I-PpoI expression plasmid and making U2OS cells stably expressing I-PpoI. A.H. performed EJ5-GFP reporter assays. A.d.G. helped with the GFP-WWP2 pull-downs for MS analysis. A.P. helped with generating WWP2 plasmids and assisted with the clonogenic survival assays. A.C.O.V. analyzed SILAC-labeled MS samples. M.S.L. helped with generating WWP2 plasmids and generated U2OS cells stably expressing GFP-tagged WWP2. E.S. and H.v.A. supervised the project and wrote the paper.

\section{References}

Abu-Zhayia ER, Awwad SW, Ben-Oz BM, Khoury-Haddad H, Ayoub N. 2018. CDYL1 fosters double-strand break-induced transcription silencing and promotes homology-directed repair. J Mol Cell Biol 10: 341-357. doi:10.1093/jmcb/ mjx050

Agarwal P, Jackson SP. 2016. G9a inhibition potentiates the antitumour activity of DNA double-strand break inducing agents by impairing DNA repair independent of p53 status. Cancer Lett 380: 467-475. doi:10.1016/j.canlet.2016.07.009

Awwad SW, Abu-Zhayia ER, Guttmann-Raviv N, Ayoub N. 2017. NELF-E is recruited to DNA double-strand break sites to promote transcriptional repression and repair. EMBO Rep 18: 745-764. doi:10.15252/embr.201643191

Bennardo N, Cheng A, Huang N, Stark JM. 2008. AlternativeNHEJ is a mechanistically distinct pathway of mammalian chromosome break repair. PLoS Genet 4: e1000110. doi:10 .1371/journal.pgen. 1000110

Blackford AN, Jackson SP. 2017. ATM, ATR, and DNA-PK: the trinity at the heart of the DNA damage response. Mol Cell 66: 801-817. doi:10.1016/j.molcel.2017.05.015

Bregman DB, Halaban R, van Gool AJ, Henning KA, Friedberg EC, Warren SL. 1996. UV-induced ubiquitination of RNA polymerase II: a novel modification deficient in Cockayne syndrome cells. Proc Natl Acad Sci 93: 11586-11590. doi:10 .1073/pnas.93.21.11586

Britton S, Coates J, Jackson SP. 2013. A new method for high-resolution imaging of $\mathrm{Ku}$ foci to decipher mechanisms of DNA double-strand break repair. J Cell Biol 202: 579-595. doi:10 $.1083 /$ jcb. 201303073

Brown JS, Lukashchuk N, Sczaniecka-Clift M, Britton S, le Sage C, Calsou P, Beli P, Galanty Y, Jackson SP. 2015. Neddylation promotes ubiquitylation and release of $\mathrm{Ku}$ from DNA-damage sites. Cell Rep 11: 704-714. doi:10.1016/j.celrep.2015.03.058

Butler LR, Densham RM, Jia J, Garvin AJ, Stone HR, Shah V, Weekes D, Festy F, Beesley J, Morris JR. 2012. The proteasomal de-ubiquitinating enzyme $\mathrm{POH} 1$ promotes the doublestrand DNA break response. EMBO I 31: 3918-3934. doi:10 .1038/emboj.2012.232

Chang HHY, Pannunzio NR, Adachi N, Lieber MR. 2017. Nonhomologous DNA end joining and alternative pathways to double-strand break repair. Nat Rev Mol Cell Biol 18: 495506. doi:10.1038/nrm.2017.48

Chou DM, Adamson B, Dephoure NE, Tan X, Nottke AC, Hurov KE, Gygi SP, Colaiacovo MP, Elledge SJ. 2010. A chromatin localization screen reveals poly (ADP ribose)-regulated recruitment of the repressive polycomb and NuRD complexes to sites of DNA damage. Proc Natl Acad Sci 107: 1847518480. doi:10.1073/pnas.1012946107

Dantuma NP, van Attikum H. 2016. Spatiotemporal regulation of posttranslational modifications in the DNA damage response. EMBO J 35: 6-23. doi:10.15252/embj.201592595

Darzacq X, Shav-Tal Y, de Turris V, Brody Y, Shenoy SM, Phair $\mathrm{RD}$, Singer RH. 2007. In vivo dynamics of RNA polymerase
II transcription. Nat Struct Mol Biol 14: 796-806. doi:10 $.1038 /$ nsmb1280

Deriano L, Roth DB. 2013. Modernizing the nonhomologous endjoining repertoire: alternative and classical NHEJ share the stage. Annu Rev Genet 47: 433-455. doi:10.1146/annurev-ge net-110711-155540

Dias JD, Rito T, Torlai Triglia E, Kukalev A, Ferrai C, Chotalia M, Brookes E, Kimura H, Pombo A. 2015. Methylation of RNA polymerase II non-consensus lysine residues marks early transcription in mammalian cells. Elife 4: e11215. doi:10.7554/ eLife. 11215

Epshtein V, Nudler E. 2003. Cooperation between RNA polymerase molecules in transcription elongation. Science 300: 801805. doi:10.1126/science.1083219

Fell VL, Schild-Poulter C. 2015. The Ku heterodimer: function in DNA repair and beyond. Mutat Res Rev Mutat Res 763: 15-29. doi:10.1016/j.mrrev.2014.06.002

Feng L, Chen J. 2012. The E3 ligase RNF8 regulates KU80 removal and NHEJ repair. Nat Struct Mol Biol 19: 201-206. doi:10 $.1038 / \mathrm{nsmb} .2211$

Galanty Y, Belotserkovskaya R, Coates J, Polo S, Miller KM, Jackson SP. 2009. Mammalian SUMO E3-ligases PIAS1 and PIAS4 promote responses to DNA double-strand breaks. Nature 462: 935-939. doi:10.1038/nature08657

Galanty Y, Belotserkovskaya R, Coates J, Jackson SP. 2012. RNF4, a SUMO-targeted ubiquitin E3 ligase, promotes DNA doublestrand break repair. Genes Dev 26: 1179-1195. doi:10.1101/ gad.188284.112

Gong F, Miller KM. 2018. Double duty: ZMYND8 in the DNA damage response and cancer. Cell Cycle 17: 414-420. doi:10 $.1080 / 15384101.2017 .1376150$

Gong F, Chiu LY, Cox B, Aymard F, Clouaire T, Leung JW, Cammarata M, Perez M, Agarwal P, Brodbelt JS, et al. 2015. Screen identifies bromodomain protein ZMYND8 in chromatin recognition of transcription-associated DNA damage that promotes homologous recombination. Genes Dev 29: 197-211. doi:10.1101/gad.252189.114

Gong F, Clouaire T, Aguirrebengoa M, Legube G, Miller KM. 2017. Histone demethylase KDM5A regulates the ZMYND8NuRD chromatin remodeler to promote DNA repair. J Cell Biol 216: 1959-1974. doi:10.1083/jcb.201611135

Goodarzi AA, Noon AT, Deckbar D, Ziv Y, Shiloh Y, Löbrich M, Jeggo PA. 2008. ATM signaling facilitates repair of DNA double-strand breaks associated with heterochromatin. Mol Cell 31: 167-177. doi:10.1016/j.molcel.2008.05.017

Hsin JP, Manley JL. 2012. The RNA polymerase II CTD coordinates transcription and RNA processing. Genes Dev 26: 2119-2137. doi:10.1101/gad.200303.112

Ishida N, Nakagawa T, Iemura SI, Yasui A, Shima H, Katoh Y, Nagasawa Y, Natsume T, Igarashi K, Nakayama K. 2017. Ubiquitylation of Ku80 by RNF126 promotes completion of nonhomologous end joining-mediated DNA repair. Mol Cell Biol 37: e00347-16. doi:10.1128/MCB.00347-16

Ismail IH, Gagné JP, Genois MM, Strickfaden H, McDonald D, Xu Z, Poirier GG, Masson JY, Hendzel MJ. 2015. The RNF138 E3 ligase displaces $\mathrm{Ku}$ to promote DNA end resection and regulate DNA repair pathway choice. Nat Cell Biol 17: 14461457. doi:10.1038/ncb3259

Jeronimo C, Collin P, Robert F. 2016. The RNA polymerase II CTD: the increasing complexity of a low-complexity protein domain. I Mol Biol 428: 2607-2622. doi:10.1016/j.jmb.2016 .02 .006

Kakarougkas A, Ismail A, Chambers AL, Riballo E, Herbert AD, Kunzel J, Lobrich M, Jeggo PA, Downs JA. 2014. Requirement for PBAF in transcriptional repression and repair at DNA 
breaks in actively transcribed regions of chromatin. Mol Cell 55: 723-732. doi:10.1016/j.molcel.2014.06.028

Kochan JA, Desclos ECB, Bosch R, Meister L, Vriend LEM, van Attikum H, Krawczyk PM. 2017. Meta-analysis of DNA double-strand break response kinetics. Nucleic Acids Res 45: 12625-12637. doi:10.1093/nar/gkx1128

Krogan NJ, Lam MH, Fillingham J, Keogh MC, Gebbia M, Li J, Datta N, Cagney G, Buratowski S, Emili A, et al. 2004. Proteasome involvement in the repair of DNA double-strand breaks. Mol Cell 16: 1027-1034. doi:10.1016/j.molcel.2004 .11 .033

Lemaitre C, Grabarz A, Tsouroula K, Andronov L, Furst A, Pankotai T, Heyer V, Rogier M, Attwood KM, Kessler P, et al. 2014. Nuclear position dictates DNA repair pathway choice. Genes Dev 28: 2450-2463. doi:10.1101/gad.248369.114

Li H, Zhang Z, Wang B, Zhang J, Zhao Y, Jin Y. 2007. Wwp2mediated ubiquitination of the RNA polymerase II large subunit in mouse embryonic pluripotent stem cells. Mol Cell Biol 27: 5296-5305. doi:10.1128/MCB.01667-06

Li J, Liu Y, Rhee HS, Ghosh SK, Bai L, Pugh BF, Gilmour DS. 2013. Kinetic competition between elongation rate and binding of NELF controls promoter-proximal pausing. Mol Cell 50: 711-722. doi:10.1016/j.molcel.2013.05.016

Luijsterburg MS, de Krijger I, Wiegant WW, Shah RG, Smeenk G, de Groot AJL, Pines A, Vertegaal ACO, Jacobs JJL, Shah GM, et al. 2016. PARP1 links CHD2-mediated chromatin expansion and $\mathrm{H} 3.3$ deposition to DNA repair by non-homologous end-joining. Mol Cell 61: 547-562. doi:10.1016/j.molcel.2016 .01 .019

Marcucci R, Brindle J, Paro S, Casadio A, Hempel S, Morrice N, Bisso A, Keegan LP, Del Sal G, O'Connell MA. 2011. Pin1 and WWP2 regulate GluR2 $\mathrm{Q} / \mathrm{R}$ site RNA editing by ADAR2 with opposing effects. EMBO I 30: 4211-4222. doi:10.1038/emboj.2011.303

Marnef A, Cohen S, Legube G. 2017. Transcription-coupled DNA double-strand break repair: active genes need special care. I Mol Biol 429: 1277-1288. doi:10.1016/j.jmb.2017.03.024

Mehta A, Haber JE. 2014. Sources of DNA double-strand breaks and models of recombinational DNA repair. Cold Spring Harb Perspect Biol 6: a016428. doi:10.1101/cshperspect .a016428

Michelini F, Pitchiaya S, Vitelli V, Sharma S, Gioia U, Pessina F, Cabrini M, Wang Y, Capozzo I, Iannelli F, et al. 2017. Damageinduced lncRNAs control the DNA damage response through interaction with DDRNAs at individual double-strand breaks. Nat Cell Biol 19: 1400-1411. doi:10.1038/ncb3643

Ohle C, Tesorero R, Schermann G, Dobrev N, Sinning I, Fischer T. 2016. Transient RNA-DNA hybrids are required for efficient double-strand break repair. Cell 167: 1001-1013.e7. doi:10.1016/j.cell.2016.10.001

Pankotai T, Soutoglou E. 2013. Double strand breaks: hurdles for RNA polymerase II transcription? Transcription 4: 34-38. doi:10.4161/trns.22879

Pankotai T, Bonhomme C, Chen D, Soutoglou E. 2012. DNAPKcs-dependent arrest of RNA polymerase II transcription in the presence of DNA breaks. Nat Struct Mol Biol 19: 276-282. doi:10.1038/nsmb.2224

Pannunzio NR, Watanabe G, Lieber MR. 2018. Nonhomologous DNA end-joining for repair of DNA double-strand breaks. I Biol Chem 293: 10512-10523. doi:10.1074/jbc.TM117.000374

Paul A, Wang B. 2017. RNF8- and Ube2S-dependent ubiquitin lysine 11-linkage modification in response to DNA damage. Mol Cell 66: 458-472.e5. doi:10.1016/j.molcel.2017.04.013

Polo SE, Blackford AN, Chapman JR, Baskcomb L, Gravel S, Rusch A, Thomas A, Blundred R, Smith P, Kzhyshkowska J, et al. 2012. Regulation of DNA-end resection by hnRNPUlike proteins promotes DNA double-strand break signaling and repair. Mol Cell 45: 505-516. doi:10.1016/j.molcel.2011 .12 .035

Ratner JN, Balasubramanian B, Corden J, Warren SL, Bregman DB. 1998. Ultraviolet radiation-induced ubiquitination and proteasomal degradation of the large subunit of RNA polymerase II. Implications for transcription-coupled DNA repair. J Biol Chem 273: 5184-5189. doi:10.1074/jbc.273.9.5184

Ray Chaudhuri A, Nussenzweig A. 2017. The multifaceted roles of PARP1 in DNA repair and chromatin remodelling. Nat Rev Mol Cell Biol 18: 610-621. doi:10.1038/nrm.2017.53

Scheffner M, Kumar S. 2014. Mammalian HECT ubiquitin-protein ligases: biological and pathophysiological aspects. Biochim Biophys Acta 1843: 61-74. doi:10.1016/j.bbamcr.2013 .03 .024

Schimmel J, Eifler K, Sigurðsson JO, Cuijpers SA, Hendriks IA, Verlaan-de Vries M, Kelstrup CD, Francavilla C, Medema $\mathrm{RH}$, Olsen JV, et al. 2014. Uncovering SUMOylation dynamics during cell-cycle progression reveals FoxM1 as a key mitotic SUMO target protein. Mol Cell 53: 1053-1066. doi:10.1016/ j.molcel.2014.02.001

Shanbhag NM, Rafalska-Metcalf IU, Balane-Bolivar C, Janicki SM, Greenberg RA. 2010. ATM-dependent chromatin changes silence transcription in cis to DNA double-strand breaks. Cell 141: 970-981. doi:10.1016/j.cell.2010.04.038

Somesh BP, Reid J, Liu WF, Søgaard TM, Erdjument-Bromage H, Tempst P, Svejstrup JQ. 2005. Multiple mechanisms confining RNA polymerase II ubiquitylation to polymerases undergoing transcriptional arrest. Cell 121: 913-923. doi:10.1016/j .cell.2005.04.010

Somesh BP, Sigurdsson S, Saeki H, Erdjument-Bromage H, Tempst P, Svejstrup JQ. 2007. Communication between distant sites in RNA polymerase II through ubiquitylation factors and the polymerase CTD. Cell 129: 57-68. doi:10.1016/j .cell.2007.01.046

Sordet O, Larochelle S, Nicolas E, Stevens EV, Zhang C, Shokat KM, Fisher RP, Pommier Y. 2008. Hyperphosphorylation of RNA polymerase II in response to topoisomerase I cleavage complexes and its association with transcription- and BRCA1-dependent degradation of topoisomerase I. I Mol Biol 381: 540-549. doi:10.1016/j.jmb.2008.06.028

Spruijt CG, Luijsterburg MS, Menafra R, Lindeboom RG, Jansen PW, Edupuganti RR, Baltissen MP, Wiegant WW, VoelkerAlbert MC, Matarese F, et al. 2016. ZMYND8 co-localizes with NuRD on target genes and regulates poly(ADP-ribose)dependent recruitment of GATAD2A/NuRD to sites of DNA damage. Cell Rep 17: 783-798. doi:10.1016/j.celrep .2016.09.037

Ui A, Yasui A. 2016. Collaboration of MLLT1/ENL, Polycomb and ATM for transcription and genome integrity. Nucleus 7: 138-145. doi:10.1080/19491034.2016.1177681

Ui A, Nagaura Y, Yasui A. 2015. Transcriptional elongation factor ENL phosphorylated by ATM recruits polycomb and switches off transcription for DSB repair. Mol Cell 58: 468-482. doi:10 .1016/j.molcel.2015.03.023

van den Boom J, Wolf M, Weimann L, Schulze N, Li F, Kaschani F, Riemer A, Zierhut C, Kaiser M, Iliakis G, et al. 2016. VCP/p97 extracts sterically trapped $\mathrm{Ku} 70 / 80$ rings from DNA in double-strand break repair. Mol Cell 64: 189-198. doi:10.1016/j .molcel.2016.08.037

van Haaften G, Romeijn R, Pothof J, Koole W, Mullenders LH, Pastink A, Plasterk RH, Tijsterman M. 2006. Identification of conserved pathways of DNA-damage response and 
radiation protection by genome-wide RNAi. Curr Biol 16: 1344-1350. doi:10.1016/j.cub.2006.05.047

Verma R, Oania R, Fang R, Smith GT, Deshaies RJ. 2011. Cdc48/ p97 mediates UV-dependent turnover of RNA Pol II. Mol Cell 41: 82-92. doi:10.1016/j.molcel.2010.12.017

Wang Q, Ma S, Song N, Li X, Liu L, Yang S, Ding X, Shan L, Zhou $\mathrm{X}, \mathrm{Su} \mathrm{D}$, et al. 2016. Stabilization of histone demethylase PHF8 by USP7 promotes breast carcinogenesis. J Clin Invest 126: 2205-2220. doi:10.1172/JCI85747

Wild T, Cramer P. 2012. Biogenesis of multisubunit RNA polymerases. Trends Biochem Sci 37: 99-105. doi:10.1016/j.tibs .2011.12.001

Wilson MD, Harreman M, Svejstrup JQ. 2013. Ubiquitylation and degradation of elongating RNA polymerase II: the last resort.
Biochim Biophys Acta 1829: 151-157. doi:10.1016/j.bbagrm .2012 .08 .002

Yang F, Kemp CJ, Henikoff S. 2015. Anthracyclines induce double-strand DNA breaks at active gene promoters. Mutat Res 773: 9-15. doi:10.1016/j.mrfmmm.2015.01.007

Yasukawa T, Kamura T, Kitajima S, Conaway RC, Conaway JW, Aso T. 2008. Mammalian Elongin A complex mediates DNA-damage-induced ubiquitylation and degradation of Rpb1. EMBO I 27: 3256-3266. doi:10.1038/emboj.2008 .249

Zhang Q, Karnak D, Tan M, Lawrence TS, Morgan MA, Sun Y. 2016. FBXW7 facilitates nonhomologous end-joining via K63-linked polyubiquitylation of XRCC4. Mol Cell 61: 419433. doi:10.1016/j.molcel.2015.12.010 


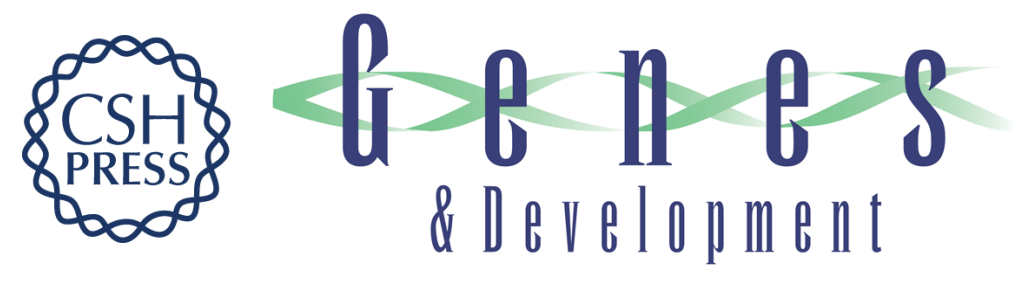

\section{WWP2 ubiquitylates RNA polymerase II for DNA-PK-dependent transcription arrest and repair at DNA breaks}

Pierre Caron, Tibor Pankotai, Wouter W. Wiegant, et al.

Genes Dev. 2019, 33: originally published online May 2, 2019

Access the most recent version at doi:10.1101/gad.321943.118

\section{Supplemental http://genesdev.cshlp.org/content/suppl/2019/04/29/gad.321943.118.DC1 Material}

References This article cites 65 articles, 15 of which can be accessed free at: http://genesdev.cshlp.org/content/33/11-12/684.full.html\#ref-list-1

Creative This article, published in Genes \& Development, is available under a Creative Commons Commons License (Attribution 4.0 International), as described at License http://creativecommons.org/licenses/by/4.0/.

Email Alerting Receive free email alerts when new articles cite this article - sign up in the box at the top Service right corner of the article or click here.

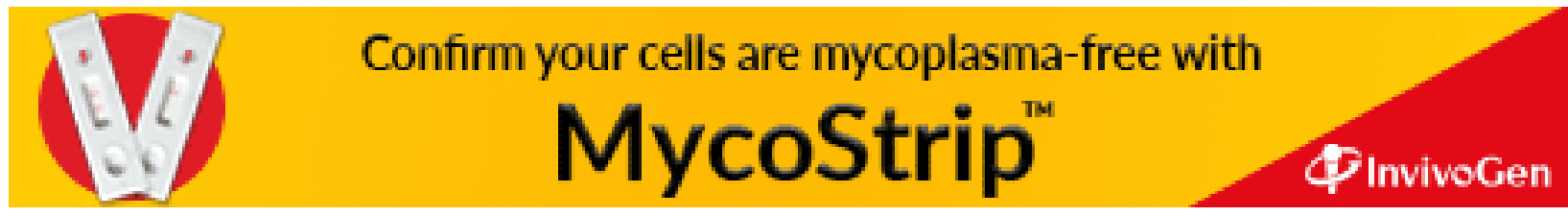

